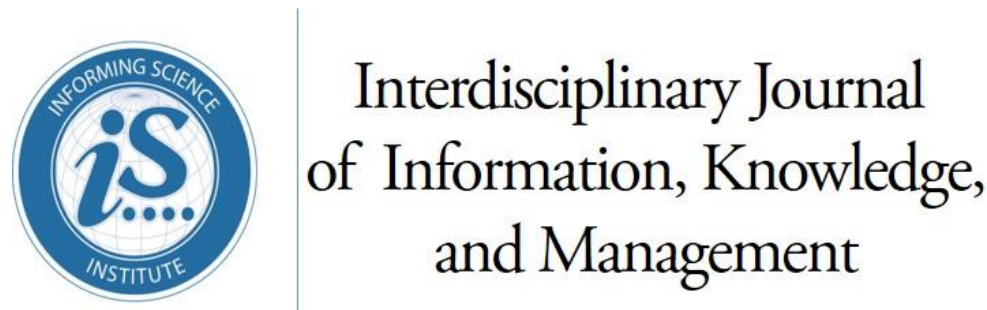

An Official Publication

of the Informing Science Institute

InformingScience.org

IJIKM.org

Volume 12, 2017

\title{
TYPOLOGY ON LEADERSHIP TOWARD CREATIVITY IN VIRTUAL WORK
}

\begin{tabular}{ll}
\hline Iris Humala & University of Tampere, Tampere, $\quad$ Humala.Iris.A@student.uta.fi \\
Finland
\end{tabular}

\section{ABSTRACT}

Aim/Purpose

This study aims to develop a descriptive typology to better identify leadership toward creativity in virtual work in different types of companies.

Background

The study empirically explores how leadership toward creativity occurs in virtual work and uses the theoretical lenses of creativity-conducive leadership and heterarchy to generate a typology.

Methodology A multiple qualitative case study design, interpretivist approach, and abductive analysis are applied. Data is collected by interviewing 21 leaders and employees face-to-face in four companies in the ICT sector and one business advisor company.

Contribution

The empirical evidence of this study enriches the understanding of leadership toward creativity in virtual work and contributes to the limited empirical knowledge on leadership that stimulates a virtual workforce to achieve creativity.

Findings

The four different types of companies in the typology utilize various transitions toward leadership creativity in virtual work. The trend in leadership in the existing virtually networked business environment is toward the "collective mind" company, which is characterized by shared values, meaningful work, collective intelligence, conscious reflection, transparency, coaching, empowering leadership by example, effective multichannel interaction, and assertiveness. The findings empirically support applying a heterarchy perspective to lead a virtual workforce toward creativity and promote leaders who are genuinely interested in people, their development, collaboration, and technology.

Recommendations The typology helps professionals realize the need to develop leadership, communifor Practitioners cation, interaction, learning, and growth to foster creative interaction and improve productivity and competitiveness.

Recommendation This study enables researchers to more rigorously and creatively conceptualize the for Researchers conditions and relationships in leadership that facilitate creativity in virtual work.

\footnotetext{
Accepted by Editor Maureen Tanner | Received: January 17, 2017 | Revised: March 22, May 8, June 21, 2017 | Accepted: July 12, 2017.

Cite as: Humala, I. (2017). Typology on leadership toward creativity in virtual work. Interdisciplinary Journal of Information, Knowledge, and Management, 12, 209-243. Retrieved from http://www.informingscience.org/Publications $/ 3786$
}

(CC BY-NC 4.0) This article is licensed to you under a Creative Commons Attribution-NonCommercial 4.0 International License. When you copy and redistribute this paper in full or in part, you need to provide proper attribution to it to ensure that others can later locate this work (and to ensure that others do not accuse you of plagiarism). You may (and we encourage you to) adapt, remix, transform, and build upon the material for any non-commercial purposes. This license does not permit you to use this material for commercial purposes. 
Typology on Leadership toward Creativity in Virtual Work

Impact on Society The findings highlight humanistic values for developing leadership. The study strengthens the view that collective creativity in virtual work cannot emerge without virtual and physical interaction in appropriate spaces and caring for each other.

Future Research Future studies may focus on other fields, industries, networks, roles of materialities, and employees in fostering creativity and on theory development. Longitudinal studies are advisable.

Keywords virtual work, creativity, leadership, typology, heterarchy

\section{INTRODUCTION}

In the face of rapid change, the complexity and importance of information and communication technology (ICT), virtuality, and mobility as well as the need to enhance innovation and productivity in today's business and work, leaders must better understand the creativity that occurs when technology and human creative processes interact (e.g., Gilson, Maynard, Jones Young, Vartiainen, \& Hakonen, 2015). The speed of digital development makes this even more important because new areas are becoming subject to automation, and people need to adapt to use their creativity in these new environments in which machines complement and augment human capabilities (Brynjolfsson \& McAfee, 2014). This situation requires identification of ways to use ICT in leadership in order to efficiently organize internal collaboration and learning and their external applications (Guo, Dilley, \& Gonzales, 2016) and an understanding of creativity as a strategic challenge in the global business environment to advance profitability in business and productivity and the common good in society. According to Chamakiotis (2014, p. 70), "creativity is pivotal in design, as it is closely linked to the problem-solving activity, as well as to the commercial success of a product."

Virtual work is actualized in dynamic multi-mediated, massive, multi-actor social networks (Panteli, 2009) that are not directed from the top down. In this kind of work, it is vital to understand the creativity that occurs between people in organizations and combine single individuals' creativity with groups' collective creativity to enable all possibilities for innovation (e.g., Sawyer \& DeZutter, 2009). "Virtual work" refers to the work performed by people in different geographical locations that use ICT to manage business processes and "virtuality" so that companies can work together with customers, users, and interest groups (Humala, 2015).

Previous research has found that it is important for leaders to foster a virtual co-presence of staff members to produce mutual trust for better interaction and outcomes (Altschuller \& Benbunan-Fich, 2010), generate participation and supportiveness in virtual work, and maintain motivation (Jenster \& Steiler, 2011). However, few studies have focused on the real-world applications of leadership toward creativity in virtual work. Few empirical studies have examined organizational creativity as a collective phenomenon, which requires researchers to study creativity in ongoing organizations (i.e., in organizations that grow) (Guo et al., 2016). Additionally, more empirical evidence is needed to apply a heterarchical perspective to virtual work and to understand the connections between stimulating creativity and heterarchy in order to foster better leadership of virtual workforces (Humala, 2016). Heterarchy has roots in complex adaptive system theory (Holland, 2006) and highlights the changing power relations within groups (Aime, Humphrey, Scott, \& Paul, 2014). This study rises to these challenges by empirically exploring how leadership toward creativity occurs in virtual work and using the theoretical lenses of creativity-conducive leadership and heterarchy in leadership to generate a descriptive typology (Collier, LaPorte, \& Seawright, 2012) including four different types of companies. According to Bell and Kozlowski (2002), a typology is especially useful in new areas of inquiry that have not been extensively explored and are characterized by a variety of diverse but related phenomena. The typology identifies leadership toward creativity in virtual work in various types of companies and defines various transitions toward creative leadership in virtual work. The typology serves as an analytical tool that helps both researchers and practitioners to understand and develop leadership toward creativity in virtual dispersed work as well as conceptualize the conditions and relationships inherent to leadership. This paper provides an elaborate understanding of the type of leadership that inspires a 
virtual workforce to be creative, including its attributes, requirements, and societal significance. For practitioners, it helps identify the characteristics that differ between various types of companies and provide new ways to foster a competitive virtual workforce.

This study is part of a research project that aims to incorporate business-oriented and pedagogical thinking in leadership by investigating the processes that occur at multiple levels of virtual work and how leaders influence the underlying processes and dynamics that lead to organizational outcomes (Dinh et al., 2014). The aim of this multifaceted approach is to help increase the success of organizations and their staff.

The next section introduces the theoretical framework of the study. The subsequent sections describe the methodology and findings of the study. The final sections discuss the results and present the conclusion.

\section{THEORETICAL BACKGROUND}

This study relates to the following academic discussions: virtuality and virtual work, creativity and collective creativity, creativity-conducive leadership approaches to virtual work versus task-focused leadership, and a heterarchical perspective in leadership versus a hierarchical perspective.

\section{VIRTUALITY AND VIRTUAL WORK}

Virtuality, as a multidimensional concept, is an organizational setup whereby operations are organized and distributed across geographical, temporal, cultural, and organizational boundaries (e.g., Parjanen, 2012). Virtuality is part of a social and conceptual network that allows interaction between people with the same interests and conceptual spaces, and it is supported by ICT and exploration both within and beyond organizations (Panteli \& Chiasson, 2008). Technological and social changes revise how we understand virtuality, its role in organizations, and its future virtuality-based perspectives for businesses.

Explorations of virtuality have expanded from individual virtual work contexts to virtual teams, organizations, and networks and mix face-to-face and computer-mediated interactions. Since technology-mediated interaction complements rather than substitutes face-to-face interaction, Dixon and Panteli (2010) define virtuality based on virtual continuities that emerge within a team when both face-to-face and technology-mediated communication are used to mitigate the perceived effects of boundaries between the two media.

Virtual work, as shown in this study, broadly includes permanent, contemporary, intra- and interorganizational, nationally, and globally dispersed work (Panteli, 2004) as well as hybrid work, which combines face-to-face and virtual communication (Griffith, Sawyer, \& Neale, 2003). In doing so, it involves specific remote work contexts and virtual teams, organizations and customers, and users and suppliers in networks. Virtual work is actualized in dynamic networks in complex contexts with multilevel patterns and social relations (Clippinger, 1999; Weil, 2009), and it includes dynamic structural arrangements (Gibson \& Gibbs, 2006; Zimmermann, Wit, \& Gill, 2008). Virtuality as a work context is a continuous, dynamic series of processes consisting of circles of circles within circles (each circle or network consists of smaller networks or teams, and each network works together in a vast network) (Zohar, 1997).

Virtual teams include groups of geographically dispersed individuals working together on a joint project or common task whose primary communication occurs electronically (e.g., Jarvenpaa \& Leidner, 1999). Research has highlighted the importance of trust for enabling people to collaborate in virtual work contexts and found that a lack of face-to-face interaction decreases productivity in truly virtual teams (e.g., Panteli \& Chiasson, 2008; Parjanen, 2012). 
Recently, scholars have focused on factors affecting knowledge sharing and outcomes in virtual organizations. Virtual contexts are also unbounded and nonlinear with free movement, enabling flexibility, fluidity, creativity, and opportunities, which lead to improvements in the innovation process (Gibson \& Gibbs, 2006; Panteli \& Chiasson, 2008). Virtual co-creation in virtual networks supports the participation of previously unavailable experts in order to arrive at innovative solutions (e.g., Panteli, 2009; Parjanen, 2012). According to Chumg, Cooke, Fry, and Hung (2015), promoting social values based on mutuality, trust, and shared goals can improve employees' sense of well-being and knowledge-sharing via ICT, hence improving the organization's competitive advantage. Moreover, perceived proximity - a symbolic representation of geographically distant coworkers - has been found to mediate the effects of communication and identification on relationship quality, reinforcing the hypothesis that critical aspects of distributed work are socially constructed and symbolically laden (O’Leary, Wilson, \& Metiu, 2014; Wilson, O’Leary, Metiu, \& Jett, 2008). Also, multiliteracy skills (e.g., Dawson \& Siemens, 2014) and an understanding of collaborative and distributive participatory media literacy based on sharing, especially the sharing of collective intelligence (Kupiainen \& Sintonen, 2010), are crucial for virtual collaboration and leadership of virtual work.

\section{CREATIVITY AND COLLECTIVE CREATIVITY}

Here, creativity is considered a joint course of action taken by everyone in an organization. Creativity, the process of generating something novel and useful, has been connected to individuals and groups, and it is said to originate from personal predispositions toward creativity and a hospitable social context (Amabile, 1988; Csikszentmihalyi, 1999; Woodman, Sawyer, \& Griffin, 1993). Amabile (1983) states that creativity arises when the following three components are present: (1) domain-relevant skills and expertise; (2) creativity-related thinking related to cognitive and personality processes that are conducive to novel thinking; and (3) task motivation, especially intrinsic motivation. She extended her theory to include teams and organizations (Amabile, 1988) and later identified the power of progress as the top motivator of performance (Amabile \& Kramer, 2011). In addition, creativity is embedded in dynamic interactional relationships between people and their cultural and material realities (Poutanen, 2016), and it needs time to arise (Uusikylä, 2012). Creativity can also be understood as divergent thinking - devising alternative solutions to problems - that produces novel and useful outputs and demands discipline, skill, hard work, and patience (Moeran, 2015; Penttilä \& Hakala, 2016).

Studies on creativity have increasingly stressed sociocultural and collective creativity (e.g., Sawyer \& DeZutter, 2009) based on Vygotsky's (1978) sociocultural approach to human learning as a social process. The interaction of individual creative skills, team dynamics, and organizational solutions leads to combined outputs (Bissola \& Imperatori, 2011; Hargadon \& Bechky, 2006). Various social resources and tools related to collaboration can promote creativity (Hämäläinen \& Vähäsantanen, 2011). For example, according to Hardagon and Bechky (2006), reflective reframing serves as the core of creatively collective moments because it draws upon participants' prior experience and combines it in new ways. The ability for people to transform the outside world and gain a sense of belonging to a community by finding creative solutions to everyday tasks and longer-term goals have been underlined as ways in which creativity is meaningful (Countlett, 2011; Handy, 1995; Zhou \& Shalley, 2008). Previous research has highlighted the role of micro-level interactions - that is, collaborative moments and events - and processes to generate collective creativity (Hardagon \& Bechky, 2006; Poutanen, 2016).

Organizational creativity refers to the creation of a new valuable and useful product, service, idea, procedure, or process by people working within a complex social system (Woodman et al., 1993). This type of creativity is related to group creativity and contextual influences (Parjanen, 2012; Schepers \& van den Berg, 2007). A relaxing environment, support for the organization's structural and leadership solutions, resources, and skills, and a positive organizational culture are essential for organizational creativity (e.g., Kallio \& Kallio, 2011; Martens, 2011). 
In order to achieve positive outcomes, it is essential for organizations that connect people from various geographic locations to understand collaborative creativity and combine it with individual creativity. In online social interactions, especially those involving problem-solving, creative cognition and communication are vital to achieve creativity (Amabile, 1998; Drazin, Kazanjian, \& Glynn, 2008; Wheeler, Waite, \& Bromfield, 2002). In virtual work contexts, it is essential for leaders to understand the creativity that occurs among people in organizations, hire the right people for the right positions, combine individual creativity with collective creativity, and support continuity and trust between employees to foster innovative collaboration (Amabile, Conti, Coon, Lazenby, \& Herron, 1996; Panteli \& Chiasson, 2008; Sawyer \& DeZutter, 2009). According to Hardagon and Bechky (2006), selecting individuals that pursue collective achievement over individual achievement, rewarding and encouraging those individuals, and requiring daily interaction between project teams are vital to foster social interactions in virtual work. Perceptions of an organizational work environment can influence the level of creativity in the organization (Amabile et al., 1996), even in virtual work environments (Cortini \& Scaratti, 2011).

\section{CREATIVITY-CONDUCIVE LEADERSHIP APPROACHES}

Leadership is defined as the process of actively influencing, motivating, and inspiring people to discover new possibilities, achieve their potential, and complete goals (e.g., Searle \& Hanrahan, 2011). Good leadership must also balance continuous change, strategic goals, renewal of business, and people's emotional states and motivation factors at work processes. Creativity-conducive leadership focuses on stimulating people and enabling relationships. It aims to foster individual and collective creativity inside an organization and outside organizational, geographical, and technological boundaries, despite the dynamic and complex nature of leader-follower interactions (Guo et al., 2016).

Leadership toward creativity involves focusing on people, understanding the power of direction, and achieving meaningful progress toward excellent outcomes (Amabile \& Kramer, 2010; Bass \& Avolio, 1993; Catmull \& Wallace, 2014). Derecskei (2016) emphasizes the responsibility of leaders and managers to not only motivate and facilitate employees' creativity but also take responsibility for their decisions. Leaders and managers can enhance their followers' intrinsic task motivation and cause them to take more cognitive risks, thereby increasing their creativity skills (Amabile, 1983). Examples of such measures include paying attention to work environments, encouraging collaboration, mapping the phases of creative work, providing paths through bureaucracy, and creating outlets for passion at work (Amabile et al., 1996; Amabile \& Khaire, 2008). Moreover, exciting tasks, freedom, permission to fail, sufficient time, rewards, positive affect, minor successes, and constructive debates support creativity in work communities (Amabile, Barsade, Mueller, \& Staw, 2005; Amabile \& Kramer, 2011; Uusikylä, 2012). In previous research on virtuality and virtual work and theories of creativity and collective creativity, the following key creativity-conducive leadership approaches are discussed: transformational leadership, emotional leadership, and complexity leadership. These approaches are connected; for example, transformational leadership involves elements of both emotional and complexity leadership. They all have a philosophical foundation in interpretivist epistemology (e.g. Hatch \& Cunliffe, 2006) and subjectivist and processual ontology, which regards reality as a social construct and leadership as continuous social flow (Crevani, Lindgren, \& Packendorff, 2010).

\section{Transformational leadership}

Transformational leadership is characterized by a clear vision and mission, inspiration, motivation, intellectual stimulation, and individualized consideration focusing on development of followers' personal growth and attention to their individual needs (Avolio \& Bass, 1988; Avolio, Waldman, \& Yammarino, 1991; Warrick, 2011). This type of leadership has been linked to employee creativity through, for instance, individual creative identity (e.g., Hu, Gu, \& Chen, 2013; Wang \& Zhu, 2011). In addition, it creates a context for more effective organizational and personal performance (Bass \& 
Typology on Leadership toward Creativity in Virtual Work

Avolio, 1993). A group's creative identity mediates the effect of group-level transformational leadership on individual creative identity through an innovative and creative climate and shared creative norms and regulations within the group (Wang \& Zhu, 2011).

Previous research has presented different views of the utility of transformational leadership in virtual work. Ruggieri, Boca, and Garro (2013) concluded that transformational leadership with a cognitive or metacognitive style is more satisfying than transactional leadership with a more participative style in online teamwork. Transformational leadership has been recognized by Schultz (2010), Kahai, Huang, and Jestice (2012), and Eisenbeiß and Boerner (2013) as creativity-conducive in virtual work environments despite empirical findings that negatively link transformational leadership to follower creativity via follower dependency. A study by Castro, Gomes, and de Sousa (2012) indicates that followers' creativity relates to transformational leadership and leaders' emotional intelligence (e.g., Coleman, Boyatzis, \& McKee, 2004). However, some researchers argue that the relationship between transformational leadership and creativity is not entirely understood (Wang \& Zhu, 2011).

Other combinations of leadership styles in virtual work have also been suggested, such as a combination of transformational and transactional leadership (Zayani, 2008) with a visionary style (Whitford \& Moss, 2009). Moreover, Wang and Rode (2010) call for greater understanding of the roles of followers and organizational context in transformational leadership processes. Recently, a study by Mittal and Dhar (2015) focusing on Indian small and medium-sized enterprises (SMEs) in the IT industry identified the relationship between the theory of transformational leadership and creative self-efficacy (CSE), which is the belief that an individual has the ability to produce creative outcomes (Tierney \& Farmer, 2002). They found that transformational leadership has a significant and positive relation to CSE and that CSE mediates the relationship between transformational leadership and employee creativity (Mittal \& Dhar, 2015).

\section{Emotional leadership}

Emotions are essential to understanding social relations while leading and working, including in virtual environments. In line with psychologist and philosopher John Dewey's theory of experience, emotion reflects the underlying dynamics of interactions between people (Alexander, 1987). Emotional intelligence (EI) refers, on the most general level, to one's ability for self-assertion, management of emotions, social awareness, and management of relationships to recognize and regulate emotions in ourselves and others (Coleman, 2001; Virtanen, 2013). It is related to social intelligence referring to individuals' social awareness and skills to effectively operate in social environments (e.g., Coleman, 2006) and interpersonal intelligence which means skills to understand the intentions, motivations and desires of other people and interact with them (Gartner, 1983). Emotional intelligence has also been defined as the emotional, affective, and social skill dimension of general intelligence (Frye, Bennett, \& Caldwell, 2006; Quisenberry, 2011) and one's ability to regulate emotions to promote emotional and intellectual growth (Mayer \& Salovey, 1997). Lewis (2010) found that social intelligence is associated with the development of trust in leader-follower relationships in virtual project teams, indicating a strong link between interpersonal relationship skills, the development of positive trust relations, and interactions in virtual environments.

The development of emotional leadership is based on EI (Bar-On, 2004; Coleman, 1998; Mayer \& Salovey, 1997). Emotional leadership considers leadership to be a social process that influences people's emotions (Nokelainen \& Ruohotie, 2006). In work-related contexts, emotional leadership is defined as one's EI-based ability to recognize, understand, and use emotional information about oneself and others in a way that leads to efficiency and excellent performance at work (Boyatzis \& Sala, 2004; Coleman et al., 2004).

As stated by Castro et al. (2012), followers' creativity is associated with leaders' EI. According to Humala (2014), leaders of a dispersed virtual workforce need EI to understand the role of emotions in revealing social relations between people and in creating a culture of experimentation and passion for unleashing creativity. Through EI and emotional leadership, it is possible to inspire people, which is 
especially important in situations where people are working in geographically disparate locations at least partly via computer-mediated tools (Humala, 2014).

\section{Complexity leadership}

The virtual working process is a self-organizing system with a non-linear organizational structure. Such a complex and dynamic environment serves as a challenge for leaders of virtual workers, who must be able to navigate complex situations. The characteristics of virtual interaction are typical of complex adaptive systems (CAS): open, evolutionary networks of communication and interdependent agents with a common outlook that are capable of creative problem solving (Uhl-Bien, Marion, \& McKelvey, 2007). This makes complexity leadership a possible type of leadership in virtual work (Lichtenstein, Uhl-Bin, Marion, Seers, \& Orton, 2006; Uhl-Bien et al., 2007).

Complexity leadership challenges traditional leadership theories. As an integrative theoretical framework, it regards leadership as a function of interaction, which is a complex interactive dynamic through which adaptive outcomes can emerge (e.g., Uhl-Bien et al., 2007). Leaders of virtual workforces should understand the importance of virtual relationships between people and be aware of ways to exploit those relationships to achieve positive outcomes (Agrifoglio \& Metallo, 2011; Zimmermann et al., 2008).

Complexity leadership relies on relationships, complex interactions between people. It influences interpersonal interactions, and clarifies the purpose of each member of the organization (Hazy, 2009). Such leaders must predict and think through complex problems, engage groups in dynamic adaptive changes, encourage innovation, and manage emotions (Plowman et al., 2007). Previous research has highlighted the need to emphasize complexity at multiple levels in organizations and networks to promote organizational creativity (Spelthann \& Haunschild, 2011) and to understand the ways in which temporal complexity influences people and organizations (Dekkers, 2009; Plowman et al., 2007). Geerlof and van Beckhoven's (2016) recent study revealed that, in addition to its ephemerality, the specificity of an organizational context influences organizations' potential for self-organization.

Focusing on the interactions between people and creating the conditions for the emergence of a new and undefined solution requires commitment from everyone in the value chain; thus, complexity leadership is neither easy nor quick (Goldstein, Hazy, \& Lichtenstein, 2010). In virtual work contexts, the process may be even more challenging. To address complexity, diversity, and uncertainty in virtual work contexts, leaders may also need to surround themselves with people to assist them and move to leadership positions if necessary (e.g., Dotlich, Cairo, \& Rhinesmith, 2008).

\section{TASK-FOCUSED LEADERSHIP}

Task-focused leadership is the opposite of leadership that inspires creativity in a virtual workforce. Task-oriented leaders focus on creating structure and engaging in transactional leadership (Derue, Nahrgang, Wellman, \& Humphrey, 2011; Warrick, 2011; Yukl, Gordon, \& Taber, 2002). To create structure, these leaders ask group members to follow standard rules and regulations, assign them to tasks and roles, maintain strict performance standards, and criticize mistakes (Derue et al., 2011). Transactional leadership (Bass \& Avolio, 1993) involves clarifying performance targets and those responsible for achieving these objectives as well as identifying mistakes and deviations from performance standards (Derue et al., 2011). Structure and routine are typical ways to correct those deviations (Borgmann, Rowold, \& Bormann, 2016). Task-oriented leaders primarily utilize directive leadership. According to Warrick (2011), transactional leadership describes the transaction that occurs between leaders and followers to accomplish the work and achieve goals. Leaders determine what needs to be done, and both parties receive something of value - for example, rewards for individuals and groups and greater productivity or conformity to standards for leaders (Humpreys \& Einstein, 2003; Warrick, 2011). These objectives are related, but leadership cannot bind the leader and followers to a continuous goal and thus cannot bind leaders to followers (Burns, 1978). 
Typology on Leadership toward Creativity in Virtual Work

Task-oriented leaders focus on planning the short-term organization of job activities; clarifying policies, responsibilities, and performance objectives by communicating the action plans and milestones needed to achieve a goal; defining the need for resources; and monitoring operations and performance (Pinar, Zehir, Kitapç1, \& Tanriverd1, 2014; Yukl et al., 2002). According to Borgmann et al. (2016), three meta-categories of leadership - relations-, task-, and change-oriented leadership, as proposed by Yukl et al. (2002) - are sufficient to explain the leadership constructs of transformational and transactional leadership, laissez-faireism, consideration of followers' needs and abilities, and the creation of structure. They argue that change-oriented leadership is most useful for predicting the job satisfaction of followers and that task-oriented leadership behavior negatively affects followers' job satisfaction (Borgmann et al., 2016). In contrast, relations-oriented leadership fosters varied commitment and job performance.

In virtual work, technology and digital communication tools play a crucial role in interaction between team members and therefore must be considered when leading a virtual workforce and eliminating factors that inhibit creativity. In general, according to Zimmermann et al. (2008, p. 331), "most taskoriented leadership behaviors as well as relationship-oriented leadership behaviors are perceived to be somewhat more important in virtual communication settings than in face-to-face communication settings." Pinar et al. (2014), who conducted a study of virtual teams in Turkey, a developing country, argue that task-oriented leadership, in which leaders determine the standards for business plans, is essential for both internal and external learning in virtual teams. According to them, as task-oriented leadership facilitates information acquisition and sharing, it allows solutions to problems to be developed quickly.

However, previous research has indicated that leaders who have a fixed mindset and focus on taskbased factors are rational, normative, and less fostering of creativity (Karwowski, 2014; Ruggieri, 2009). Karwowski (2014) attempted to determine whether creativity is fixed or growth-based and demonstrated the inhibiting effects of a fixed mindset on creative problem-solving. Further, power relations and power negotiations between organizational members influence creativity; for example, biased power relations and steep hierarchies may disrupt creativity (Poutanen, 2016). Purvanova and Bono (2009) maintain that relational leadership behaviors may suffer if task-oriented communication displaces social-relational communication. Moreover, as stated by Ocker (2005), the creative performance of virtual teams is inhibited by dominance, domain knowledge, downward norm setting, a lack of shared understanding, time pressure, and technical difficulties. Previous studies have shown that organizational creativity is a function of group creativity and contextual influences (Schepers \& van den Berg, 2007; Parjanen, 2012). This indicates that leaders who focus on the tasks that must be done and who are uninterested in how people work and interact with each other and the contexts in which people are working have unfavorable mindsets for enhancing organizational creativity.

\section{HETERARCHY IN LEADERSHIP}

This study is based on the ontological commitment of leaders in a heterarchy (Spelthann \& Haunschild, 2011). In a heterarchy, organization is regarded as a multi-layered entity with overlapping parts and organizational slack. Leadership in a heterarchy is shared and enables interaction, meaningful work, inspiration, and creativity (Crumley, 2005; Spelthann \& Haunschild, 2011). An ontological commitment in a knowledge-based system, like leadership in virtual work, means that "an agent commits to an ontology if its observable actions are consistent with the definitions in the ontology" (Gruber, 1995, pp. 908-909). Heterarchy as an ontological commitment is appropriate for leadership toward creativity in virtual work as it helps leaders comprehensively understand their role in virtual work and stimulates discourse and interaction to release people's creativity (Humala, 2016).

McCulloch (1945) first used the concept of heterarchy in nervous nets in neuroscience to demonstrate that the human brain functions in a heterarchical way, re-ranking values as circumstances change (Crumley, 2005). Citing Crumley (2005, p. 45), the concept of heterarchy is an approach "to identify ranked and unranked values, behaviors, and organizations as they shift in time, space and 
cognitive frame." Heterarchy is also useful in conflicts or inutilities when old approaches are inactive but useful elements are preserved for new, creative solutions (Crumley, 2005).

Heterarchy is an organizational form of distributed intelligence (Stark, 2009) focused on collective good (Stephenson, 2009). It refers to the lateral coordination of corporate diversity in both organizational structure and environment and to the relation of elements to one another when they are unranked or ranked in different ways (Crumley, 1995). Heterarchy relates to power defined as "the ability to get others on board with enthusiasm and zeal" (Grant, 2012; Staw, 2016, p. 8). As stated by Aime et al. (2014), the theoretical core of the concept of heterarchy integrates several distinct bodies of literature that highlight the changing power relations within groups.

In heterarchical structures, power actively and legitimately fluctuates among team members to align their capabilities with changing situational demands (Aime et al., 2014; Crumley, 2005). Heterarchical organizations are typically segmentary, polycentric, and networked. Stephenson (2009) refers to a heterarchy as a "virtual organization," stressing the importance of trusted heterarchical interconnections via technology. He highlights hidden connections that are invisible to a hierarchy but are essential for management and sustainability, arguing that hidden strategic connections - that is, significant collaborators - make the partnership work and reveal the organizational form of the heterarchy.

Heterarchies are also complex adaptive systems (CASs) that interweave many principles of organization and involve interdependent relations between participants (Girard \& Stark, 2002; Holland, 2006). According to Spelthann and Haunschild (2011), the complexity of a heterarchy need not be solved or explained away. Instead, it is one robust arrangement that facilitates embedded organizational creativity. Stark (2009) sees heterarchies as cognitive ecologies that facilitate reflexive cognition. Distributed authority with reflection and discussions at multiple levels (Girard \& Stark, 2002) and careful coordination among increasingly free units of an organization (Stark, 2009) have been proposed as ways to achieve heterarchy and cope with complex interdependencies. Girard and Stark (2002) stress the relevance and importance of organizational properties such as incongruence, organizational slack, structural overlap, and latency in analyses of organizational creativity because these issues are related to corporate and institutional heterarchy, which makes creative organizations possible.

\section{HIERARCHICAL LEADERSHIP}

In terms of power relations, hierarchy is in a dialectical relationship with heterarchy (Crumley, 2005). A hierarchy uses authority and legitimate power to create and coordinate horizontal and vertical divisions of labor (Adler, 2001). In other words, it is a tall structure with many levels of hierarchy. Hierarchy is a principle of organization originating from Frederick W. Taylor's management principles, which were proposed in the early 20th century, and from military and religious organizations. One example of a hierarchy is a bureaucracy, which developed as organizations spread out laterally and work was divided into specialized departments in order to create a stronger structure with the ability to grow and handle more complex tasks (Lipnack \& Stamps, 1999).

Hierarchical organizations focus on power, authority, and value control, which means that leaders engage in planning, instruct their employees on what to do and how to do it, and closely supervise them. Typical characteristics of hierarchical organizations are rule-based authority, a control-based definition of power, value exclusivity, a status quo, clear social distinctions, and substantial costs for security (Crumley, 2001). According to McGuire, Palus, Pasmore, and Rhodes (2015), in command and control leadership cultures, authority and control are prioritized, and success depends on obedience and loyalty to authority. The drawbacks of hierarchies are their one-way paths of information, conservative approach, vulnerability to change, emphasis on keeping things running smoothly, and a tendency to publicly smooth over mistakes (Lipnack \& Stamps, 1999; McGuire et al., 2015). 
Typology on Leadership toward Creativity in Virtual Work

People at different levels in an organization may experience hierarchical leadership differently. According to Jago and Vroom (1977), people may feel powerless when they are not able to actively participate in decision-making. Often, these feelings occur in the presence of autocratic methods, in which the actual decision-making process is participative but involves only people at high levels in the organization (Jago \& Vroom, 1977).

Virtual collaborative work contexts question traditional leadership, which is hierarchical and authoritarian (e.g., Houglum, 2012). Democratic organizations include characteristics of both hierarchy and heterarchy (Crumley, 2001). Lipnack and Stamps (1999) noted that the 21st-century organization is comprised of virtual teams and networks of teams and that this new type of organization is complex and networked, not pyramidal, involving hierarchy, bureaucracy, small groups, and distinct networked relationships. Recently, Hoch and Kozlowski (2014) discovered that virtuality weakens the relationship between hierarchical leadership and performance but improves the relationship between structural supports and performance.

It is vital for future learning and growth for organizations to match their leadership culture and operational needs. A hierarchy can be efficient for routine tasks but makes it difficult to implement an innovative, agile strategy and carry out innovation activities, during which new knowledge arises via creative collaboration (e.g., Adler, 2001; McGuire et al., 2015). Citing Clemen and Reilly (2014, p. 239), "hierarchical organizational structures can hinder creativity, which, in turn, can be exacerbated by autocratic supervisors."

\section{RESEARCH METHODOLOGY}

\section{RESEARCH OBJECTIVES}

This study aims to develop a descriptive typology based on empirical data to identify and describe how leadership occurs in virtual work in various types of companies. The research question is "How is leadership toward creativity made up in different types of companies in virtual work?" To answer this question, the following objectives were defined: (1) produce a descriptive typology of different company types by analyzing what, how, and why leadership toward creativity occurred in virtual work in the case companies; and (2) analyze four different types of companies in detail to identify the composition of each type.

A basic qualitative research approach was used to answer the research question and enhance the understanding of leadership toward creativity in virtual work. An interpretivist approach and a focus on meaning were applied to get close to the people and process under study (Hatch \& Cunliffe, 2006).

\section{DATA GATHERING}

A multiple-case study was performed. The data is based on 21 face-to-face interviews with five female and ten male leaders and four female and two male employees aged roughly 20-60 years employed at five companies in Finland. Two of the employees were interviewed in English, and the others were interviewed in Finnish. Finland is a country in northern Europe with 5.5 million inhabitants, an open economy dependent on global trade, extensive ICT integration, and increasing production and distribution of digital products and services through various information networks. Finland's digital operational environment is being reformed to develop practices that are more functional and flexible. This situation makes virtual work in Finland similar to that in the rest of the world and allows the findings to be generalized to other virtual dispersed work contexts around the globe, especially those related to service.

Two of the case companies were start-ups. The first start-up is a multinational company founded in 2011 that has a workforce of 12 people. Its headquarters are located in the Netherlands and its research department is in Finland. It operates in the global advanced ICT industry, especially in Asia, and uses virtuality in its professional internal and external communication. The other start-up, which 
was founded in 2014, is in a beginning phase and employs 3-4 people. It operates virtually in the software industry in Finland and cooperates with Vietnamese organizations. The third case company is a Finnish SME with 130 employees working in the ICT service sector in different locations in Finland. It was initially founded over 100 years ago. It uses virtual tools in various ways to enhance transparency in business. The fourth company is large and was founded over 30 years ago. It offers real-time automated financial management solutions at several locations in Finland and employs more than 300 people. The SME and the large case company mainly operate in Finland. The fifth case company is a one-person business advising enterprise utilizing virtual tools to cooperate with its customers and partners at different locations in Finland. Its experienced owner has worked in leadership positions and as an entrepreneur in other fields of business and thus can offer different perspectives on the issue under study.

When recruiting cases, the goal was to find companies of different sizes that operate in part across national borders. The field of industry was considered during the recruitment process. Companies operating in the ICT sector were most interested in participating in this study because they regarded leadership that fosters creativity and supports successful collaboration in virtual work as important for their businesses. Even though there are differences in virtual labor between industries, there are also notable similarities. Because the ICT industry is most familiar with using ICT tools to achieve work-related collaboration, in a way it is a pioneer of virtual work and inspires virtual workforces to achieve creativity. Half of the case companies operated primarily globally, and many participants had previous experience in global business and virtual work. Therefore, the chosen case companies can be regarded as representative in this study as they align well with the main types of company profiles that exist in virtual contexts.

The semi-structured interviews were conducted from April to June 2016 and each lasted 1 to 2 hours. The two start-ups that operate globally were recruited first. One person was interviewed through Skype, and all the others were interviewed face-to-face. A semi-structured format was chosen for the interviews as it enabled the interviewees to discuss issues that were relevant to them, and open-ended questions made it possible for the researcher to hear respondents' full stories. The chosen theoretical lenses of virtuality and virtual work, creativity and collective creativity, creativity-conducive leadership, and heterarchical leadership guided the interview protocol. The questions focused especially on leading a virtual workforce toward collective creativity and interaction and the outcomes of that kind of leadership as well as the interviewees' views regarding the development of leadership toward creativity in virtual work. The conversations with the interviewees concerned how, why, where, and in which kinds of actions and events leadership toward creativity occurs and makes sense in virtual work as well as the physical, social, and virtual distance virtual workers experience and the relevance of distance to leadership toward creativity. Additionally, the respondents were asked to describe which kinds of outcomes leadership toward creativity in virtual work generates (e.g., for individuals, virtual teams, network partners, and customers) as well as how creativity and its exploitation can be better enhanced in virtual work. Echoing Brinkmann (2012), the "social" is comprised of experience, discourse, and objects. During data gathering and analysis, focus was placed on the experiences of human beings, their interactions, and virtual tools and other material objects that enhance creativity in virtual work (Brinkmann, 2012). Presentation materials and news about the case companies supplemented the interview data.

\section{DATA ANALYSIS}

Each interview was recorded and transcribed, which resulted in 474 pages of transcripts. Direct identifiers were removed from the interview data. The data was analyzed both during data collection and after all the data was received. Field notes, comments, and questions were written down during the data collection stage and examined later. The interview transcripts were read through several times, coded, and analyzed by one researcher. ATLAS.ti version 7.5.10, qualitative data analysis and research software developed by ATLAS.ti Scientific Software Development GmbH, was used during the coding phase. Figure 1 describes the entire analysis process. 
The data was first coded by identifying single phrases from the raw data to help reach the aim of the research. Second, the codes were grouped into themes. Next, the themes were incorporated into five sections of leadership toward creativity in virtual work - separately in the SME and large case company and jointly in the two start-ups and business advising company. Thus, three summaries with the following five headings were created:

1. Appearance of leadership

2. Outcomes of leadership

3. Factors inspiring creativity

4. Development needs in leadership

5. Practices toward learning and exploiting know-how

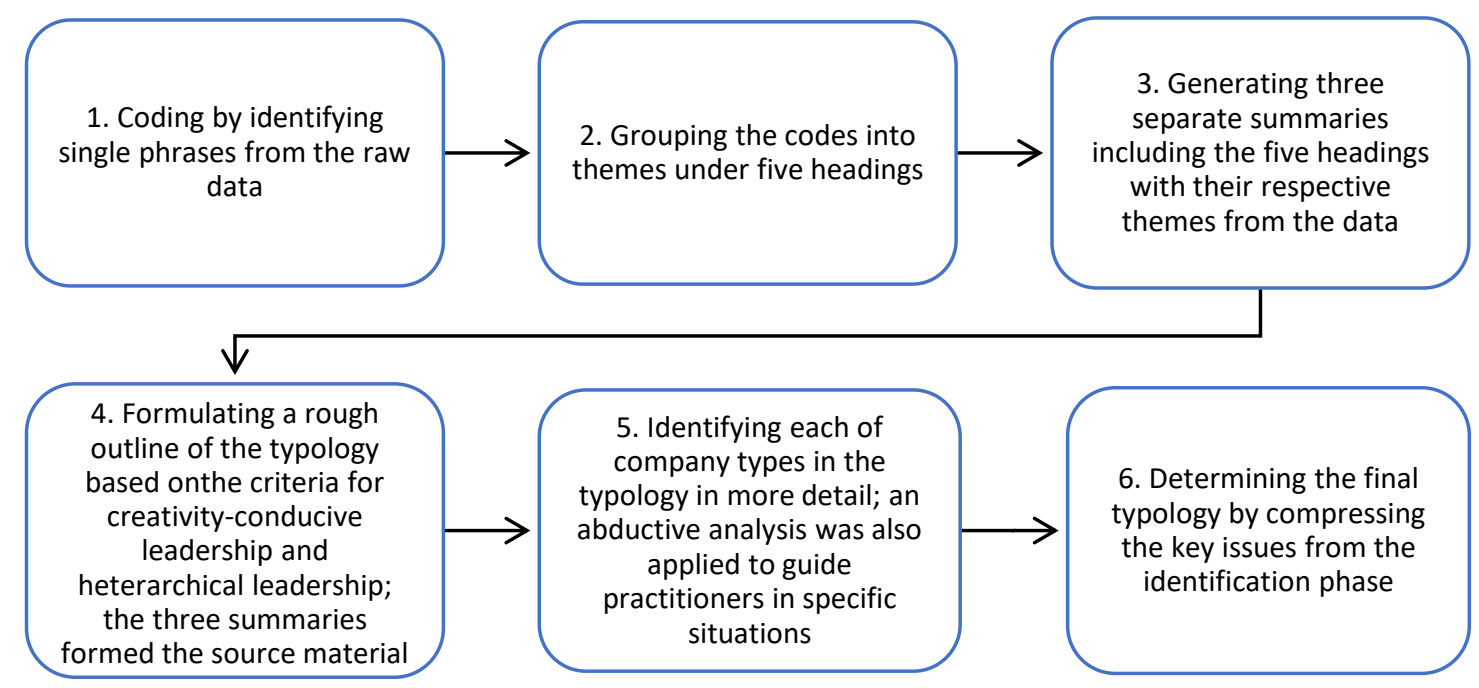

Figure 1. The analysis process

The research problem guided the analysis process. The primary theoretical lenses - leading a virtual workforce toward creativity and heterarchy - functioned as tools with which to tackle the data analysis. The researcher responded to all information that positively or negatively related to the primary theoretical lenses when reading and rereading the raw data, identifying single phrases from the raw data, and grouping the codes into themes. Problems and shortcomings were highlighted by the interviewees and information that negatively related to the primary theoretical lenses of the study was noted in the raw data and included in the themes. In other words, the aim of identifying single phrases from the raw data was to detect all possible issues the interviewees had brought forward.

The researcher's experience in management practice and theory and personal interest in linking educational and business knowledge influenced the data gathering and analysis. The researcher also provided reports of the initial study findings to the SME and large case company after the interviews. The five headings mentioned above formed the primary structure of these reports. The reports enabled the researcher to reflexively elaborate upon the analysis.

A descriptive fourfold typology was used as a framework for analyzing responses to leadership toward creativity in virtual workforces in case companies. The concepts and associated terms located in the cells of a typology constitute the cell types, which are related to "the overarching concept and the categories of the row and column variables provide the defining attributes" (Collier et al., 2012, p. 228). In the descriptive typology, the dimensions and cell types help identify and describe the phenomenon under analysis. The overarching concept measured by the typology is leadership toward creativity in virtual work. 
The analysis consisted of three phases: 1) forming a rough outline of the typology, 2) identifying each of the company types in the typology in more detail, and 3) determining the final typology. A rough outline of a descriptive typology based on two dimensions aimed to identify the typical characteristics of leadership toward creativity in virtual work in each type of company. Two key theoretical lenses, creativity-conducive leadership and heterarchical leadership, were used to generate a typology of four modes of leadership with ontological commitment. The theoretical approaches also served as tools to detect the unnoticeable in everyday life such as beliefs and hidden power structures (Brinkmann, 2012). The descriptive typology is comprised of dependent and intervening variables in studies of leadership toward creativity in virtual work. Two dimensions of the dependent variable - leadership focus - were analyzed: leadership inspiring creativity among a virtual workforce and leadership with a task-based mindset. In addition, two dimensions of the key intervening variable, ontological commitment to leadership, were analyzed: heterarchical integrative leadership and hierarchical authoritarian leadership. These four dimensions established the rows and columns of the typology; on the vertical axis, leadership inspiring creativity in a virtual workforce increases upward, and on the opposing side, leadership with a task-focused attitude increases downwardly, while on the horizontal axis, heterarchical integrative leadership increases to the right and hierarchical leadership increases to the left. Cross-tabulating these dimensions yielded four company types: type A, "nascent launch pad"; type B, "collective mind"; type C, "command center"; and type D, "leaky boat."

The outline of the typology was created with criteria based on a previous explorative study (Humala, 2016) that used document-based inquiry to identify focal relations between challenges in leading a virtual workforce toward creativity and a heterarchical ontology of leadership. The two theoretical lenses guided the location in which creativity-related and heterarchy-related data were placed in the typology. Those themes that did not relate to creativity and heterarchy were placed in other corners of the typology. The criteria for creativity-conducive leadership used in the analysis are the four main challenges of leading a virtual workforce toward creativity (LC): understanding virtuality as a networked work context (LC1), developing a virtual leadership mindset (LC2), leading meaningful work towards progress (LC3), and energizing people (LC4). Accordingly, the criteria for heterarchical leadership are the four attributes of heterarchical leadership $(\mathrm{AH})$ : a combination of organization principles (AH1), supportive interdependent interaction (AH2), authority distributed to best complete work (AH3), and reinforcement of creativity and innovative ideas (AH4).

The three summaries, including the five headings and their themes, formed the sources used for the analysis and subsequent typology. The study started from the viewpoint of creativity-conducive leadership. The three summaries were thoroughly explored, and the relationships between each theme in the three summaries and the four criteria for creativity-conducive leadership (LC1-LC4) were analyzed. If a theme and any creativity criteria (LC1-LC4) were found to be interrelated, that interrelation was indicated by a blue mark on the corresponding creativity criterion. Typification continued by analyzing themes related to heterarchy criteria, and any interrelations were indicated in red on the appropriate heterarchy criteria (AH1-AH4).

Next, the ways in which each of the LC and AH criteria were positioned in relation to different themes in the three summaries were analyzed. In other words, the amount of LC and AH symbols in each theme suggested how important creativity-conducive leadership and heterarchical leadership were to that theme. For instance, if a theme had several LC symbols, but only one AH symbol, the theme in question was significantly related to leadership that inspires creativity, but not heterarchical leadership. Based on the position of LC and AH symbols in different themes in the three summaries, it was possible to specify the angle of the typology at which each theme belonged. To complement the analysis and preliminary typology, original interview transcripts as well as field notes, comments, and questions were reread several times to re-check the interrelations between LC and AH symbols and the themes. During the first phase of analysis, creativity- and heterarchy-related themes located at the appropriate corners of the typology were chosen from each of the three summaries. Those 
themes that did not relate to creativity and heterarchy were chosen for the other corners of the typology.

During the second phase of analysis, the composition of each type of company was investigated in more detail. The four types of companies were analyzed and described systematically to offer detailed information about leadership and how it appears to both leaders and employees in each company type (i.e., what, how, and why different characteristics are related to leadership toward creativity in virtual work). An abductive form of analysis (Brinkmann, 2014) suggested by researchers of process organizational studies and complex systems (e.g., Langley \& Tsoukas, 2010) was used during this phase of analysis. It served as a supplemental form of analysis that allows the typology to guide practitioners in situations and highlight behavior and practices to avoid in the future (Staw, 2016). The abductive form of analysis is not data-driven, nor theory-driven, but breakdown-driven (Alvesson \& Karreman, 2011) and is typically used in situations of uncertainty when it is necessary to understand something that happens (Brinkmann, 2014).

Three different but related analytic strategies suggested by Brinkmann (2012) for research on everyday life were applied during the abductive analysis process. First, a phenomenological strategy was employed to make the obvious clearer by focusing on how leadership toward creativity in virtual work appears to human beings. Second, a critical strategy was used to make the hidden obvious by trying to uncover the hidden power structures that regulate human behaviors and influence leadership that aims to inspire a virtual workforce. Third, a deconstructive strategy was applied to make the obvious dubious by questioning what is taken for granted and showing that meanings and understandings are unstable and ambiguous, for example, by bringing to light the different ways in which leadership toward creativity in virtual contexts can appear to different people.

Rereading the themes and original data from interviews and analyzing them using the three analytic strategies helped the researcher take note of surprising issues, such as those that arose in situations of instability, when it is hard to proceed as usual (Brinkmann, 2012; Dewey, 1938). During the abductive analysis, the research problem guided the searching process to further explore what the data reveals about the phenomenon under study, determine to interpret the relevant findings, and make sure that the issues were placed in the right corners in the typology. The second stage of analysis also focused on how humans' experiences, interactions, virtual tools, and material objects are taken into consideration when leading a virtual workforce in different types of companies (Brinkmann, 2012).

An abductive form of analysis helped the researcher reread the themes and original data from the interviews and analyze the themes again to ensure that the themes were accurately located in the typology. While rereading the themes and original data, it was revealed that issues focusing on how leadership toward creativity in virtual work appears to human beings (phenomenological strategy) were mainly discussed under the headings "appearance of leadership" and "outcomes of leadership" in the three summaries. Further, hidden power structures (critical strategy) and issues to be questioned (deconstructive strategy) were discussed under the headings "factors inspiring creativity," "development needs in leadership," and "practices toward learning and exploiting know-how."

The analysis in the identification phase highlighted three aspects of business related to creativity and heterarchy when leading a virtual workforce: (a) leadership as an experience outcome, (b) communication and interaction as essential tools in leadership, and (c) learning and growth as key objectives in leadership. These aspects help to compare different types of companies in the typology. Moreover, they expose major issues related to leadership toward creativity in virtual work that must be considered and reveal the ways in which different features are related to each other and have consequences (cf. Dewey, 1938).

During the third phase of the analysis, the final typology was determined by combining the key issues in the identification phase with each of the four company types in the typology. In line with current 
theoretical understandings, the key issues in each company type are categorized as one of three critical aspects of business: leadership, communication, and learning and growth. The next section presents the findings of this study.

\section{RESEARCH FINDINGS}

\section{COMPOSITION OF THE FOUR TYPES OF COMPANIES}

Identification of the four company types resulted in detailed specifications of the three critical aspects of business related to leading virtual work - leadership, communication and interaction, and learning and growth - in each type of company. Tables 1-4 present an accurate description of the composition of each type of company as well as the abductive analysis focused on breakdowns and inconsistencies of the activity. Identification of the company types also allowed discussion of the challenges that each type of company likely faces and their leadership-related actions (i.e., what leadership toward virtual work involves and why) (cf. Dubé, Bourhis, \& Jacob, 2006). Extracts from interviews with employees of the case companies offer concrete examples of the critical aspects of business in each type of company.

\section{Table 1. Composition of company type A, "nascent launch pad"}

\section{ASPECT OF}

BUSINESS

Leadership

Common objec-

tives are inspir-

ing, and a vir-

tual leadership

mindset and or-

ganizing princi-

ples are devel-

oping

Communication

and interaction

Communication

and interaction

are not transpar-

ent and support-

ive enough to

fully energize

people

\section{Learning and}

growth

Recruiting and

committing the

right profession-

als and develop-

ing their know-

how are key for

achieving mean-

ingful growth

\section{COMPOSITION OF “NASCENT LAUNCH PAD” COMPANIES}

Common inspiring purpose based on strong previous know-how

The knowledge and resources for leading people and managing data and projects are inadequate; vague areas of focus make employees confused

Moving from prototype to project leadership and sharing responsibilities is regarded necessary to improve employees' commitment

Self-leadership needs improvement; employees find leaders difficult to contact, and working time is lost while waiting for final decisions

Courses of action are not open enough for virtual work; unclearly justified plans are hard to understand, which makes it difficult for leaders to convince employees of new ideas

Problems related to communication and interaction are recognized and managed slowly; for example, new older employees may not ask advice from younger ones who are more knowledgeable; more face-to-face and virtual interaction is needed to build a stronger sense of community

Creating an inspiring multicultural working culture presents problems; for example, employees may not understand the importance of mutual communication and interaction with others, including on social media

Creating new resources or facing a lack thereof enables and requires continuous learning

Visionary and trustworthy team members are necessary for growth, but uncertainty about the future creates challenges to recruiting the right professionals that are committed; leadership toward creativity may enable the right people to be hired

To avoid disintegration, leaders may need to guide employees' development toward a common objective and seek a balance between the objective and the enthusiasm and creativity of single employees or small groups 


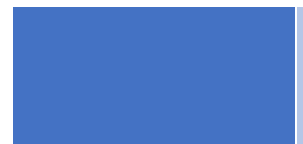

Better orientations and more frequent face-to-face work sessions are necessary to teach new remote employees, virtually brainstorm - especially in cases of foreign language communication - and increase employee commitment

The detailed analysis of "nascent launch pad" companies indicates that moving from a prototype to project leadership and sharing responsibilities is regarded as important for success. A shared inspiring vision and business objectives motivate, enable, and require continuous learning. However, difficulties arise regarding recognition and management of communication problems ahead of time when leading people, managing data and projects, and leading oneself. One of the interviewees describes the situation as follows:

So, the good thing is that I learn many new things because I need to do [things] by myself and not have any mentor. But it is sometimes very frustrating because I don't know what to do, and because of the delay from the boss, so I just need to wait about [for instructions on] what I need to do next. (male employee, about 20 years old)

The following extract from one interview highlights the challenge of facilitating mutual interaction and a common working culture for employees from different cultures:

Have you ever talked together about virtual work, this way of working, culture, and problems and challenges you bave encountered? (interviewer)

Not enough. In fact, not at all. In a way, organizing interaction is more emphasized [in virtual work], so that it is not only one-way communication but that everyone tries one's best in communication, so that communication is not a self-evident fact... you need to do something together physically, and not only that "okay, now we met"... Now, when we have had a group in social media for a while for commenting and discussing... at least, I have got a feeling that we are in some common space when we are in that group. This situation requires indirect leadership, and that everyone is actively building the community spirit. (male leader, about 30 years old)

The uncertain future of the business creates recruiting challenges, and the development of employees' expertise requires leaders to have more know-how. However, the findings of this study indicate that leadership toward creativity may help recruit the right people for virtual work. Orientation and collaborating face-to-face are crucial for employees to learn, develop new solutions, and increase their commitment to the project.

Table 2. The composition of company type B, "collective mind"

\begin{tabular}{l|l}
$\begin{array}{l}\text { ASPECT OF } \\
\text { BUSINESS }\end{array}$ & \multicolumn{1}{l}{ THE COMPOSITION OF TYPE B, "COLLECTIVE MIND" } \\
\hline $\begin{array}{l}\text { Leadership } \\
\text { Value-based leadership by example aims at common meaningful values, business objec- } \\
\text { tives, and a communal course of action; to be successful, a leader must be positive and } \\
\text { enthusiastic } \\
\text { sertive leader- } \\
\text { ship by example } \\
\text { and collective } \\
\text { intelligence re- } \\
\text { flect an under- } \\
\text { standing of vir- } \\
\text { tuality as a } \\
\text { whole }\end{array}$ & $\begin{array}{l}\text { tion; challenges, responsibilities, and survival awaken employees' creativity and passion } \\
\text { for work; encouraging different views and experiments and permitting failure enables } \\
\text { power and commitment to arise in the virtual community; group pressure controls be- }\end{array}$ \\
$\begin{array}{l}\text { Assertiveness and consistent leadership with clear common rules and expectations are } \\
\text { needed; root causes of problems must be clarified, and solutions must be implemented; } \\
\text { sufficient documentation, communication, and skillful project management reduce } \\
\text { risks }\end{array}$ & $\begin{array}{l}\text { Open and active dialogic interaction through multiple up-to-date communication chan- } \\
\text { nels helps a virtual workforce internalize values, broaden views about work, and feel se- } \\
\text { cure enough to question present practices and reflect on issues; this requires regular }\end{array}$ \\
\hline $\begin{array}{l}\text { Communication } \\
\text { and interaction }\end{array}$
\end{tabular}


ASPECT OF

BUSINESS

Distances can

decrease differ-

ences, and ac-

tive, up-to-date

multichannel

communication

supports helpful

interaction

\section{Learning and}

growth

Coaching lead-

ership with par-

ticipatory learn-

ing and skillful

recruiting and

orientation im-

proves both

meaningfulness

and business

\section{THE COMPOSITION OF TYPE B, “COLLECTIVE MIND”}

face-to-face meetings between managers and employees, especially in problem situations, and broad connectivity to customers

Physical distances can decrease social pressure, decrease cultural differences in communication, and cause people to work together more closely and efficiently

Sharing know-how and helping fellow team members require social skills such as small friendly signs, positivity, responsiveness, accepting people with different backgrounds, and emotional and social intelligence to perceive emotions; these are early indicators of the quality of interactions and course of the business

The right types of physical workspaces support mutual interaction and pride in work

Face-to-face and online leadership and sufficient resources for it create perseverance and sustainable business in virtual work; leaders are interested in getting to know employees on a more personal level and caring for them, respecting and listening to them, receiving feedback from them, and highlighting their success stories; performance quality assessment and influential personal and group compensations are in use

Coaching leadership encourages people to bring forward their personalities, strengths, know-how, and interests; clear targets and freedom to make plans, constructive feedback and resources, and respect for employees' private life generate flexibility, commitment, personal sense of success and well-being, and willingness to encourage others and share and create know-how

Participatory learning over role boundaries in authentic work tasks; accepting dissimilarity, crossing borders, an active follow-up of trends, participating in networks, and discovering new solutions and resources to help everyday work, collaborate in virtual development projects generates and utilizes development ideas across hierarchies and teams, including customers and networks

New requirements in virtual work are specified, introduced, and considered in recruiting and orientation; e.g., leaders need more orchestration expertise; specific tools in recruiting can help to get to know new remote employees better

The findings of the detailed analysis of company type B, "collective mind," indicate the importance of collective intelligence, shared responsibilities (e.g., Hyypiä \& Parjanen, 2013), leaders' intrinsic motivation, resources for leaders to orchestrate collective work, and assertiveness, as highlighted in the following:

[The leader in virtual work] must be interested in people. There is an enormous strain to lead people beneath the surface... When you genuinely talk. with people, trust emerges. First, people get the courage to bring the problems to the table and then ideas. When they see that the ideas come true and new kinds of doings, new businesses, right alignments develop from them, and they learn to see that the collective intelligence genuinely steers this company, not only one or two persons... Finally, it is a question of the fact that everyone wants to be in such an environment, where people take care of you. (male leader A, about 40 years old)

The role of a leader's intrinsic motivation and leadership example aligns with Toom's (2016) belief that a talented individual's actions have a positive influence on the success of actions taken by communities. The results of this study support Thow's (2007), which concern organizing around intelligence, and Johnson's (2015), which concern innovation arising from the group level involving structured investments and requiring executives to know how to train their teams to improvise. The analysis reveals the importance of social norms and non-hierarchically organized social forces to control behavior in work communities (Post, 2001). The data indicate that leaders that are able to coach employees obtained their skills from previous experience participating in sports, coaching sports teams, or playing in bands. 
Open and active dialogic communication and mutual interaction through the skillful use of multiple communication channels - including face-to-face and social media - as well as sharing know-how and helping each other are typical features of "collective mind" companies. Reflection with colleagues and members of professional networks in face-to-face and social media situations allows leaders to maintain their enthusiasm, creativity, and well-being. Below is an example of skillful communication:

I have two different ways to be reachable: one is electronic visibility, and the other is direct contact. I am systematically visible [on] certain electronic channels, but you must make this [available] where people are working [by] themselves... it is active work all the time. In this way, I am far and near at the same time. The geographical distances disappear when you communicate with people actively. (male business manager, about 40 years old)

Physical distances can balance cultural differences, decrease social pressure, and support knowledgesharing and helping each other, as highlighted in the following:

The social pressure decreases when the physical distance increases... In fact, virtuality equalizes cultural differences in communication in a certain way. It creates a certain rhythm that is common to all, not culture-bound, and that may even help to work in global teams. (male leader B, about 40 years old)

Moreover, the findings revealed the importance of appropriate physical workspaces for inspiring creativity in virtual work.

Empowering and coaching people to learn and grow require understanding and compassion for others in organizations (Staw, 2016). As the following example shows, leaders that coach their employees may have obtained skills from their previous experiences:

I am a former athlete and coach myself. In coaching, I have always learned that when we have training, I give instructions to the team members, and in game situations, I only give support and advice and encourage them, but then, the responsibility is on the field. In principle, the situation is the same in business. (female business manager, about 50 years old)

The significance of participatory learning compared to role boundaries in authentic work tasks is emphasized:

Our creativity should focus on the needs of customers... By bringing people around the problems of clients and by seeking for the solutions together, your own work becomes truly meaningful... This generates organizational creativity, which enhances human capital and innovativeness. (female leader, about 50 years old)

This finding supports the views of Aarnio and Enqvist (2016) and Reeves, Herrington, and Oliver (2002) regarding the importance of authentic learning tasks in learning environments in the digital age to awaken individuals' intrinsic motivation, engage those individuals, and ensure that dialogic know-how is used to achieve success. Dialogue is defined as collaborative thinking based on equal participation and familiarity with an issue or activity (Aarnio \& Enqvist, 2016).

Table 3. The composition of the company type C, "command center"

\begin{tabular}{ll}
$\begin{array}{l}\text { ASPECT OF } \\
\text { BUSINESS }\end{array}$ & THE COMPOSITION OF TYPE C, "COMMAND CENTER" \\
\hline $\begin{array}{l}\text { Leadership } \\
\text { Decision-making } \\
\text { authority being } \\
\text { entirely at the } \\
\text { top and non- } \\
\text { transparency } \\
\text { frustrate people }\end{array}$ & $\begin{array}{l}\text { Pyramid-like organization with a top-down chain of command to ensure the com- } \\
\text { pletion of tasks; hierarchy dates from the history of the company or the industry and } \\
\text { cision-making and smaller brand offices prevails }\end{array}$ \\
$\begin{array}{l}\text { Delays due to the concentration of decision-making, complicating work and hindering } \\
\text { development; unnecessary checking; abrupt occasions of "fighting fires" cause delays }\end{array}$
\end{tabular}




\begin{tabular}{|c|c|}
\hline $\begin{array}{l}\text { ASPECT OF } \\
\text { BUSINESS }\end{array}$ & THE COMPOSITION OF TYPE C, “COMMAND CENTER” \\
\hline & $\begin{array}{l}\text { and frustration, constricting creativity; managers do not get enough support and } \\
\text { coaching from leaders } \\
\text { Non-transparency; the economic situation is not openly informed, and decisions are } \\
\text { not justified and shared, so they can easily be felt to be unfair; this makes the situation } \\
\text { difficult for the middle managers to perceive and weakens the quality of their decision- } \\
\text { making and motivation } \\
\text { Cost leadership; quantitative figures and money assess work }\end{array}$ \\
\hline $\begin{array}{l}\text { Communication } \\
\text { and interaction } \\
\text { Insufficient sup- } \\
\text { port for internal } \\
\text { cooperation and } \\
\text { energizing leads } \\
\text { to a weakened } \\
\text { community spirit }\end{array}$ & $\begin{array}{l}\text { Even though new technologies and different software solutions are successfully ap- } \\
\text { plied in production, internal communication in virtual work is not felt to be even- } \\
\text { handed; interaction between departments, teams and people is weak and irregular; su- } \\
\text { periors seldom visit remote offices } \\
\text { Emotions of employees are not optimally recognized, which can make employees } \\
\text { withdraw into themselves and not openly interact with leaders, e.g., when people work } \\
\text { alone without colleagues and support from an immediate superior, or information is } \\
\text { not shared with them } \\
\text { Technical communication problems, insufficient resources for up-to-date communica- } \\
\text { tion tools, and IT Helpdesks weaken knowledge-sharing and community spirit } \\
\text { Physical work environments do not support virtual dispersed work sufficiently; people } \\
\text { work in isolation from their own colleagues; the space for internal and customer inter- } \\
\text { action is insufficient }\end{array}$ \\
\hline $\begin{array}{l}\text { Learning and } \\
\text { growth } \\
\text { Diversity and } \\
\text { ideas are not re- } \\
\text { inforced, em- } \\
\text { ployee confi- } \\
\text { dence declines, } \\
\text { and a company's } \\
\text { prospects dim }\end{array}$ & $\begin{array}{l}\text { Silo effect; diversity among the workforce is not utilized, and knowledge about differ- } \\
\text { ent approaches and customers is not shared over role boundaries; people may not } \\
\text { know who knows what or dare not share information to secure their superiority and } \\
\text { jobs; remote employees feel that cost-optimization is unfair for them to attend com- } \\
\text { mon meetings and develop their expertise } \\
\text { Failures are not spoken of and no lessons are learned from them; e.g., failures can } \\
\text { be mentioned only after many years } \\
\text { The orientation of new employees and team-building are inadequate; employees are } \\
\text { left alone without peer-support } \\
\text { The lack of a business-like course of action weakens employee confidence in leader- } \\
\text { ship and the organization, and business growth stalls; employees' and leaders' views on } \\
\text { the solutions and situations can differ from each other; remote offices do not develop } \\
\text { as planned }\end{array}$ \\
\hline
\end{tabular}

Type C, "command center," represents a pyramid-like organization in virtual work with a traditional cost-oriented leadership mindset. The costs of working virtually are assessed by money, not benefits:

Money talks [a lot], for instance, concerning [software] licenses and other issues [essential for virtual work]. Always, when you start to speak that something creates extra costs, it would be worth [it to measure] them a little concerning the benefit you get from that. I think that money has quite a significant role in a certain way. (female employee $\mathrm{A}$, about 40 years old)

This type of company succeeds in completing tasks. Some of its downsides are top-down power that does not recognize people's emotions can "make others speechless" (Tost, Gino, \& Larrick, 2013), delays in decision-making and not enough modern communication for the digital age. The significance of emotions and emotional consequences are highlighted in the following: 
Typology on Leadership toward Creativity in Virtual Work

No machine can transmit feelings...it requires different resources from employees. (female employee, about 60 years old)

In my opinion, the problem also related to the person; I can say that the leader was completely narcissistic. Then, I experienced my role as a filter, and I tried to build such a wall and be fully out of the daily necessary work and only protect your own team members, so that they could do their jobs in peace... Over two years, it was so hard, [...] there was no sense. I can say quite honestly that in that situation, I was all out leaving, because you do not tolerate that endlessly. That was not worth it. (male district manager, about 60 years old)

Moreover, the silo effect, a lack of orientation, hiding failures and a lack of trust complicate work, decreasing business growth. People do not share know-how and practices:

I don't know if I do my job in the same way as they do, for instance, in the [city A] team, I can easily have a different practice of my own, and they in the [city B] team can have their own as well. It can completely differ from that which would be an official way to do that job. (female employee B, about 40 years old)

Table 4. The composition of the company type D, "leaky boat"

\begin{tabular}{|c|c|}
\hline $\begin{array}{l}\text { ASPECT OF } \\
\text { BUSINESS }\end{array}$ & THE COMPOSITION OF TYPE D, "LEAKY BOAT" \\
\hline $\begin{array}{l}\text { Leadership } \\
\text { Business objec- } \\
\text { tive and leader- } \\
\text { ship culture are } \\
\text { felt to be con- } \\
\text { fusing }\end{array}$ & $\begin{array}{l}\text { Invariably changing organization principles and objectives, without accurately de- } \\
\text { termining the success of the previous ones, confuses people } \\
\text { Efforts to share authority have not succeeded, and micromanagement in leadership } \\
\text { prevails; leaders and managers have unclear responsibilities, and they give employees } \\
\text { contradictory directives and continuously check issues and intimidate employees; em- } \\
\text { ployees are not aware of how to apply common instructions, which complicates work } \\
\text { and the building of communal spirit } \\
\text { Attention to people is illusory, and key indicators for leadership are ignored; } \\
\text { leaders do not care about their employees' emotions, keep promises to them, or sup- } \\
\text { port them face-to-face in their work-related problems; nobody interferes in disturbing } \\
\text { or wrong behavior; these circumstances dilute employees' motivation, confidence, and } \\
\text { commitment } \\
\text { Unworkable incentives and compensations; e.g., monetary incentives do not work for } \\
\text { groups not committed to reaching a common objective }\end{array}$ \\
\hline $\begin{array}{l}\text { Communication } \\
\text { and interaction } \\
\text { Communication } \\
\text { in virtual work } \\
\text { is backward and } \\
\text { does not sup- } \\
\text { port interde- } \\
\text { pendent interac- } \\
\text { tion }\end{array}$ & $\begin{array}{l}\text { Sense of alienation and a lack of confidence in others' competence to interact; none } \\
\text { or few face-to-face interactions and informal meetings can make employees feel alien- } \\
\text { ated and unmotivated; they do not get to know their managers and colleagues and do } \\
\text { not receive enough help from their managers or know who could help them } \\
\text { Standard codes of conduct are not functioning or are lacking; people do not discuss } \\
\text { various views and attitudes together; leaders repetitively reschedule agreed meetings } \\
\text { with their employees; employees do not know how others do their work, and therefore } \\
\text { they cannot determine whether or not their treatment is fair } \\
\text { Deficient investments in face-to-face meetings and up-to-date digital communi- } \\
\text { cation tools and their use; continuous technical problems irritate people }\end{array}$ \\
\hline $\begin{array}{l}\text { Learning and } \\
\text { growth } \\
\text { Culture of in- } \\
\text { competence and } \\
\text { hidden know- }\end{array}$ & $\begin{array}{l}\text { Incompetent leadership hampers growth; leaders may be egocentric, pass over their } \\
\text { superiors, favor friends, have unnatural roles, or have no interest in developing employ- } \\
\text { ees' expertise and careers; leaders are unable to make decisions, keep their word, or del- } \\
\text { egate tasks; they must guide their employees continuously because they do not demand } \\
\text { enough from them }\end{array}$ \\
\hline
\end{tabular}


how kill meaningfulness and creativity at work
Hidden know-how and blaming others dilute enthusiasm toward new work structures and methods the knowledge and ideas of the personnel are not utilized and developed; ideas and proposals are rejected, killing employees' initiative; the roots of problems cannot be found; failures are experienced as disgraceful; issues are exaggerated or hidden; this situation can lead to uncertainty about the future employment and to conflicts, resignations, stress, and burnout in both leaders and employees

Recruiting and orientation do not support competence development in virtual work; e.g., competent experts may be hired into leadership positions, where they are no longer competent; skill requirements in virtual dispersed work are not specified; orientation is neglected

In type D, "leaky boat," leaders have a task-oriented mindset, without a clear common objective, and with illusory attention to people. Further, people find micromanagement practices confusing. Incompetence among leaders and managers, especially during recruiting and orientation, and secret knowledge make the business shaky. The following extract highlights the culture of incompetence:

We have a culture of incompetence in this organization...the problem in leadership is that we have a culture, where a right expert, a good employee, is typically promoted to a superior position. It works only to a certain point... When you build an organization, you must be very careful that a person does not fall to a level of incompetence. Leadership and HR should think about these issues in advance and have the courage to ask the individuals in question if they want to be a superior and if they are ready for that. (male leader, about 55 years old)

Digital communication know-how and tools are not resourced enough, and people feel alienated, as described in the following:

I will quickly say goodbye soon. I have worked here [alone for] two years, and this absorbs so much, that it seems that a whole other life has taken second place. I am always so tired at home that I don't feel up to doing anything... Everything goes to working hard, which does not give anything, so you just do and do out of necessity... If you just got some feedback and such, it would probably bring you effort and cope. But I believe that I have reached the end of the road. (female employee $\mathrm{C}$, about 40 years old)

Next, the final typology of leadership toward creativity in virtual work is demonstrated.

\section{TYPOLOGY OF LEADERSHIP IN FOUR TYPES OF COMPANIES}

The main findings of this study are illustrated in a descriptive typology on leadership toward creativity in virtual work (Figure 2). The four types of companies in the typology are named as type A, "nascent launch pad," type B, "collective mind," type C, "command center," and type D, "leaky boat." To help compare different company types with each other in the typology, each company type is categorized under three critical business sections in relation to creativity and heterarchy in leading a virtual workforce: (a) leadership as an experience outcome, (b) communication and interaction as key tools in leadership, and (c) learning and growth as key objectives in leadership. The vertical axis of the typology represents leadership stimulating creativity in a virtual workforce versus leadership with a task-based mindset, and the horizontal axis represents heterarchical integrative leadership versus hierarchical, authoritarian leadership. Leadership encouraging creativity in virtual work in the vertical axis can also be interpreted to reflect competitive markets as in organizational form, where creativity is necessary for success and freedom is essential for creativity. It is noteworthy that none of the case companies can unambiguously be positioned in a single company type in the typology. The different types of companies specified in the typology are not necessarily represented as purely in reality. These various types may also be simultaneously active in real-life companies (cf. Seeck \& Kantola, 2009).

Type A, "nascent launch pad," represents a company type in which leaders aim to enhance the creativity of a virtual workforce by implementing a hierarchic leadership. This type is most typical in early-stage companies, which have strong know-how and an inspiring vision, but where leadership 
and management are in progress and mostly traditional. Instead, type B, "collective mind," has already passed its infancy and has restructured its organization and leadership toward heterarchical integrative leadership while highlighting and fostering the importance of creativity in a virtual workforce. Value-based leadership by example, effective mutual interaction, collective intelligence, assertiveness, and empowering leadership are typical characteristics of this company type. The bottom of the typology highlights leadership with a task-based mindset. Type C, "command center," in the lower left corner represents a traditional company type, which implements hierarchic leadership. Decision-making authority being at the top, joint communication being comparatively slight and closed, and the silo effect characterize this company type. Integration through heterarchy without paying attention to people and their effective interaction results in unsustainable success. Instead, people feel confused about the business and do not trust their leaders and colleagues.

\section{Leadership inspiring creativity in a virtual workforce}

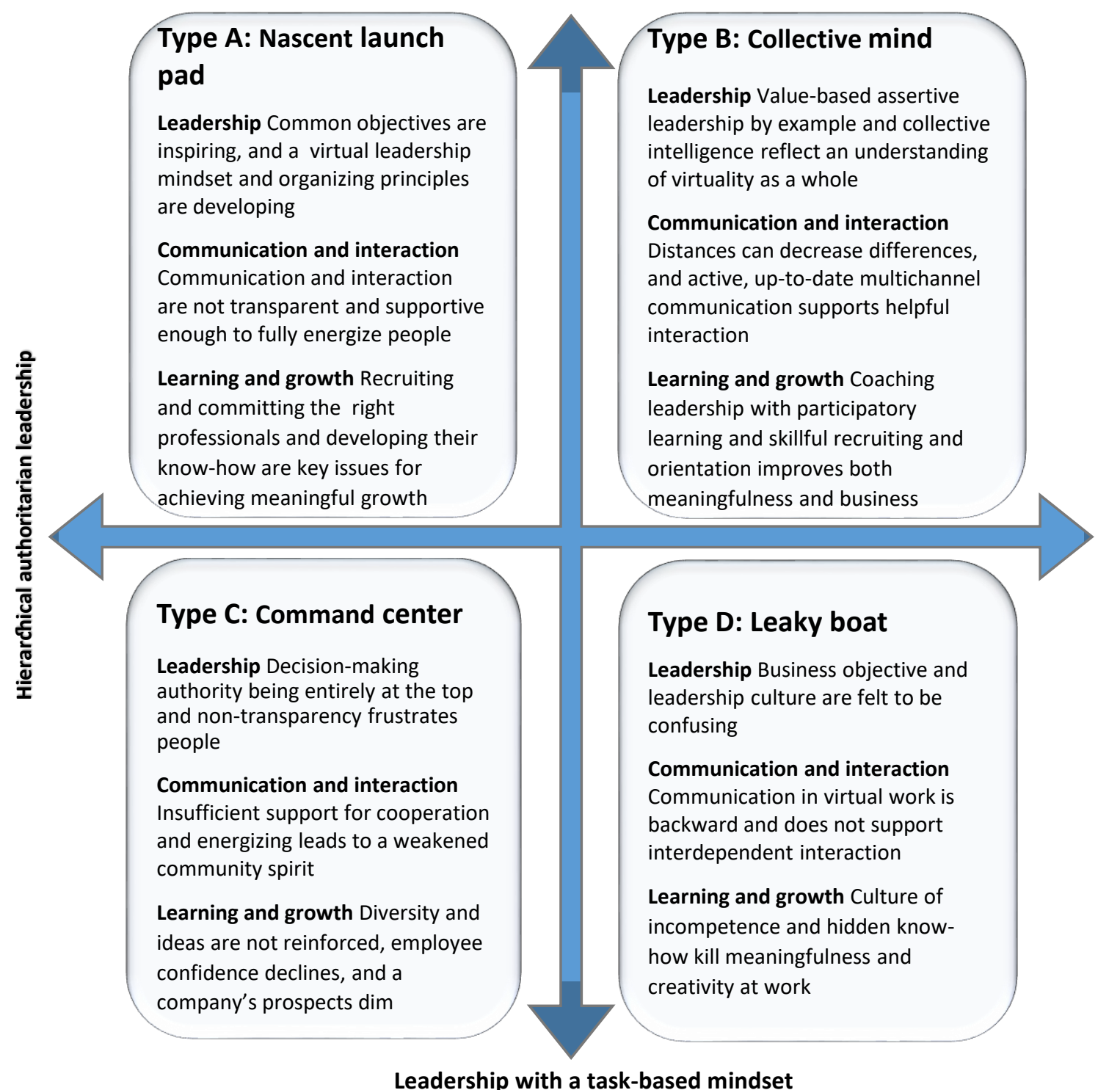

Figure 2. Typology on leadership toward creativity in virtual work

The next section discusses the findings of the study. 


\section{Discussion}

This study aimed at developing a descriptive typology to identify and describe leadership toward creativity in virtual work. Based on the empirical interview data, the study analyzed the typical aspects regarding what, how, and why leadership toward creativity in virtual work is comprised in each company type and specified the composition of each type in detail. The different types of companies define alternative trajectories in the transition toward leadership creativity in virtual work. This typology extends the leadership typologies of Dubé et al. (2006) and Hara, Shachaf, and Stoerger (2009).

The main contributions of this study are discussed below.

\section{EMPIRICAL ENRICHMENT FOR UNDERSTANDING LEADERSHIP TOWARD CREATIV- ITY IN VIRTUAL WORK}

The typology based on empirical data from multiple cases enriches the understanding of leadership that fosters creativity in virtual work and contributes to applying the heterarchy perspective to such leadership. As an analytical tool, it helps researchers draw out underlying dimensions that influence leadership toward creativity in virtual work and more rigorously and creatively understand and conceptualize the conditions and relationships in leadership that are related to each other. The categories of the typology can also be used for the classification of companies and leaders.

Type B, "collective mind," is of particular concern, as it most completely represents both leadership inspiring creativity in a virtual workforce and developing a virtual business in line with heterarchy and collective intelligence. It supports the previous research findings (Humala, 2016) about the appropriateness of heterarchical ontological commitment to leadership toward creativity in virtual work. The empirical evidence in this study affirms that leaders stimulating creativity in a virtual workforce need to understand virtuality as a networked context and apply distributed authority to orchestrate work. The finding of assertiveness in type B, "collective mind," strengthens the view about combining different organizing principles to foster creativity in virtual work and hence supports the heterarchical criteria of the combination of organizing principles (AH1). It supports the previous results of Hoch and Kozlowski (2014) regarding virtuality enhancing the relationship between structural supports and performance as well as those of Humala (2015) in a start-up context. Further, full connectivity to customers and regular personal face-to-face meetings in communication, coaching leadership with participatory learning over role boundaries, and skillful recruiting and orientation suggest that energizing people (LC1) is also an important factor in leading a virtual workforce toward creativity.

\section{LEADERSHIP TOWARD CREATIVITY IN VIRTUAL WORK ACTUALIZES IN A COLLEC- TIVE-MIND COMPANY}

The descriptive typology strengthens the view that in the present business characterized by globally operating networks and more technologically advanced contexts, the trend in leadership is toward that in type B, "collective mind." Organizational leadership needs to be updated toward a virtual leadership culture to foster collective creativity. The characteristics of a virtual leadership culture are collective intelligence, an open and communal way of working together, and shared responsibility to reach a common objective. This culture echoes Poutanen's (2016) view on a culture of working together, understanding the process, embracing variation and context, encouraging emergent practices, identifying levels of creativity, appreciating subjectivity, and developing communication to enhance collective creativity. The findings suggest that the creativity of a virtual workforce is best fostered and superior business outcomes are reached in type B, "collective mind," where both leadership toward creativity and heterarchical integrative leadership are applied. Type B, "collective mind," operates via a virtual mindset. Its characteristics include shared values with an important objective, collective intelligence, active and assertive leadership by example, transparency, shared power and responsibility, a helping culture, and empowering and coaching leadership. As leadership in this type enables power 
and commitment to arise from the community, it resembles emergent (Chamakiotis, 2014) or ad hoc leadership (Hara et al., 2009) that enables transient leadership opportunities for people. A leader who has a virtual mindset and understands virtuality as a networked context internalizes the concept that leadership and context are intricately intertwined (Osborn, Uhl-Bien, \& Milosevic, 2014). Based on this study, leadership toward creativity in virtual work requires leaders who are genuinely interested both in people, their development, and collaboration with them, as well as in the technologies. In type B, "collective mind," intrinsically motivated people work together toward a common objective in a participatory culture, where people help each other, share knowledge (Prasad, 2014) through multichannel communication, and reflect on matters and phenomena to learn to enhance business.

From a critical point of view, since people are the focus here, consideration must be given to such emerging issues as the limitations in human energy and resources with regard to continually working toward creativity and innovations, and in time and space to enable concentration on particular assignments. Further, careful reasoning is necessary regarding how to avoid the phenomenon of collective misbelief as well as to readjust after the sudden breakdowns that are inevitable in complex environments. Because organizations differ from each other, type B, "collective mind," can appear differently in various organizations and parts of them. To ensure the continuous development of resources, individuals in virtual work may be able to work in type B "collective mind" organizations only occasionally; meanwhile, the work requires organizing in a new way, and people must do different work. This may also mean finding new business models. These kinds of considerations cause the role of conscious reflection to become increasingly important in virtual work - both inside organizations and together in interest groups - so that both people and businesses can navigate in the virtual business environment as optimally as possible. As heterarchy emphasizes, shared leadership and changing roles in virtual networked work are crucial; this can also enable human beings to calm down and rediscover their intrinsic motivation and creativity.

In type A, "nascent launch pad," both the development of company leadership practices and the organization of mutual interaction are in progress. This company type has enthusiasm toward developing new ideas and practices but it is still struggling with its development. Type C, "command center," is led by hierarchy, which generates a lack of confidence among people and leads to difficulties in managing a business in the virtual environment. In type D, "leaky boat," the overall culture of incompetence does not allow either the virtual workforce or the business to flourish. The findings in virtual contexts support Amabile (1998), who highlighted that when creativity is killed, an organization loses a potent competitive weapon that enables it to create new ideas, and it can also lose the energy and commitment of its employees

\section{LEADERSHIP TOWARD CREATIVITY REQUIRES APPROPRIATE VIRTUAL AND PHYSI- CAL SPACES AND TOOLS FOR MULTICHANNEL COMMUNICATION}

Through communication, people exchange information and construct individual and contextually shared frames of reference (Poutanen, 2016). Appropriate knowledge-processing and communication that fosters the criticality and reflexivity of both individuals' own and others' ideas are important in the creative process (Mononen, Tynjälä, \& Kallio, 2016; Poutanen, 2016). This situation makes the role of communication, a helpful and friendly communication style, and communication spaces and tools critical in leading a virtual workforce toward creativity. The findings support Chamakiotis (2014) notion of the crucial role of good communication and organizational skills in creativity.

Based on the results, leaders need to utilize ongoing multichannel communication, be visible to their employees and collaborators, and work actively for their groups of people in order to succeed in dispersed virtual work. Fostering collective creativity in the virtual context requires the development of social bonds between organizational members, who can freely voice criticism when necessary to reach a common meaningful target. This development of social relationships demands not only inhibiting people's defense systems but also enabling people to meet each other face-to-face and work physically close together (Porges, 2011). The study indicates that both functional virtual and physical 
spaces are necessary for genuine mutual interaction and collective creativity to develop. The findings of this study challenge the design of future physical working spaces to foster individual and collective creativity by respecting different ways of working and by enabling practical solutions for mutual interaction, private discussions, and intense concentration - in offices, hubs, homes, or mobile work settings. The study strengthens the view that collective creativity in virtual work requires physical interactions in suitable physical spaces and the emergence of caring for each other.

As outlined previously, virtual leadership closely relates to materialities such as virtual communication tools. Leaders need to meet their virtual workforces face-to-face regularly and use modern communication tools, such as social media, to develop social bonds with the virtual workforce and to reflect issues inside the company and with customers and other stakeholders. Leaders who inspire creativity in virtual work tend to be more open-minded about trying and using alternative and multiple tools in leading people, making the obvious dubious (Brinkmann, 2012) in the present business contexts, and activating people toward a collective intelligence.

To improve the quality of virtual communication, leaders must communicate and interact horizontally between people, which is also suggested by the heterarchical perspective. This requirement challenges leaders to develop the horizontal capability of people to consciously and appropriately develop their thinking, understand reality from multiple perspectives, and change their space of consciousness according to the situation (Jakonen \& Kamppinen, 2016).

The results suggest that distances in virtual work can equalize cultural differences, decrease social pressure, and support people in working together more closely and efficiently. This finding is encouraging for developing leadership in technologically advanced dispersed contexts to piggyback diversity and different know-how to inspire a virtual workforce toward creativity and innovations in collaboration. In a sense, people in virtual settings operate in no-man's land, which enables leaders, together with their collaborators, to create similar working cultures of their own and let collective intelligence lead the organization toward common success. However, this kind of collective mind organization emphasizes the demand for emotional intelligence, sensitivity, and transparency on the part of leaders, who must also receive bad news in business and understand the interlinear hints from their people in orchestrating the collaborative work. Further, developing cultures of collective intelligence creates broader social foresight and reflexivity, allowing organizations to match science and technology and respond to the emerging near-term future context (Jakonen \& Kamppinen, 2015). These circumstances signify shared power and responsibility in virtual work.

\section{Supporting PRofEssional GRoWth AND KNOW-HoW ENHANCES COLLECTIVE CREATIVITY AND SUSTAINABILITY IN VIRTUAL WORK SETTINGS}

In general, the findings highlight developing leadership in virtual labor and the physical and virtual spaces in accordance with humanistic values to care for and empower people and support their professional growth, self-regulation, and meaningfulness at work, which will in turn foster collective creativity, utilize know-how, and promote the common good in society.

This kind of leadership enhances sustainability both for people and for business. The findings support the recent discussions on emerging pedagogies (Gros, 2016) and meaningful work (LipsWiersma \& Wright, 2012) with clear challenges, transparency, using different forms of knowledge, and integrating the use of technology as a mindset for creativity, collaboration, and multimedia productivity. This position relates to a development culture in company type B, "collective mind," which advances empowering and integrating heterarchical leadership.

Echoing previous research (Amabile et al., 1996; Nie \& Kosaka, 2014), this study empirically supports the significance of the recruiting and orientation of suitable new leaders and employees to enhance creativity in a virtual workforce and to make virtual work successful. The person-job-fit and the recruitment of more skilled persons for the leadership positions have been found to be important for increasing motivation and enhancing creativity and its utilization (O'Connor, 2016; Staw, 2016). 
Together, the findings empirically support applying the heterarchy perspective in leading a virtual workforce toward creativity. The study suggests that humanity, authentic shared values, empowerment, active and assertive leadership by example, transparency, sharing power, and encouraging a virtual workforce to assume more responsibility in organizations are key actions for inspiring creativity in a virtual workforce. However, successful empowerment in the digital era requires that leaders learn about their people and their expertise, skills, passions, and interests beyond the role limits and support their utilization. Moreover, ICT and modern multichannel communication media must be well resourced, and everyone at work should be encouraged to use them smartly to share know-how and knowledge genuinely.

The typology helps practitioners understand how leadership, communication and interaction, and learning and growth are inextricably tied together in virtual contexts as well as how they all need to be developed to foster creative interaction and improve productivity and competitiveness. It helps in identifying the characteristics that differ among the various types of companies and in realizing the connections between leadership and creativity and the role of ICT technology in developing leadership that inspires creativity and success in virtual work. Practitioners can also utilize the typology in evaluating their personal job performance and in developing suitable performance assessment indicators for both leaders and employees in virtual work.

\section{CONCLUSION}

This study developed a descriptive typology on leadership toward creativity in virtual work based on empirical case studies in five companies. The typology enriches the theoretical understanding of leadership that fosters creativity in virtual work by defining alternative trajectories in the transition toward leadership creativity in virtual work. As an analytical tool, it helps researchers draw out underlying dimensions that influence leadership toward creativity in virtual work and better understand and conceptualize the conditions and relationships in leadership that are related to each other. It can also be useful for the classification of companies and leaders.

The findings empirically support applying the heterarchy perspective to lead a virtual workforce toward creativity and affirms that leaders seeking to stimulate creativity in a virtual workforce need to understand virtuality as a networked context, apply distributed authority to orchestrate work, and also be assertive. As heterarchy emphasizes, shared leadership and changing roles in virtual networked work are crucial; this can also enable people to recover after intensive and exhausting work periods and rediscover their intrinsic motivation and creativity.

The study stresses that leaders who are genuinely interested both in people, their development, and collaboration with individuals, as well as in the technologies, can inspire collective creativity and promote the common good in society. Based on the results, in the present business involving globally operating networks and more technologically advanced contexts, the trend in leadership is toward collective-mind companies. Such companies operate following a virtual mindset. Their characteristics include shared values and meaningful work, collective intelligence, transparency, coaching, and empowering leadership by example with participatory learning beyond role boundaries, dynamic multichannel interaction, skillful recruiting and orientation, and assertiveness. However, a collective-mind company can appear differently in various organizations and parts of them. The role of conscious reflection on the ways to organize work and business models is crucial in virtual work - both inside organizations and together in interest groups - so that people and companies can navigate in the virtual business environment as optimally as possible.

The results highlight that leadership toward creativity requires appropriate virtual and physical spaces and tools for multichannel communication. The study strengthens the view that collective creativity in virtual work requires physical interactions in suitable physical spaces and caring for each other to create social bonds within the virtual workforce as well as with stakeholders. The future design of physical working spaces needs to respect different ways of working and enable practical solutions for mutual interaction, private discussions, and intense concentration - in offices, hubs, homes or mobile 
work settings. Further, ICT and modern multichannel communication media must be well resourced, and everyone needs to be encouraged to use them to share know-how genuinely. To improve the quality of virtual communication, leaders must communicate and interact horizontally between people and develop the horizontal capability of people to develop their thinking consciously; this is also suggested by the heterarchical perspective. These findings encourage the development of leadership in technologically advanced dispersed contexts to piggyback diversity and different types of knowhow to inspire a virtual workforce toward creativity and innovations in collaboration.

To succeed in empowerment in the digital era, leaders need to understand their people and their expertise, skills, passions, and interests beyond the role limits and support their utilization. The findings highlight developing leadership in virtual work and the physical and virtual spaces in line with humanistic values to care for and empower people and promote their professional growth, self-regulation, and meaningfulness at work in order to foster collective creativity, utilize know-how, and promote the common good in society. This kind of leadership both energizes people and enhances sustainability, both for individuals and businesses.

The typology helps practitioners realize the need to develop leadership, communication, and interaction, to prioritize learning and growth to foster creative interaction, and to improve productivity and competitiveness. Practitioners can also utilize the typology in evaluating their personal work performance and in developing suitable performance assessment indicators for both leaders and employees in virtual work. The typology can act as a foundation for workforce education and provide new ways of creating a competitive virtual workforce.

Regarding limitations, the data in this qualitative study were collected by one researcher almost entirely in the ICT technology and service sector in Finland, as the novelty of the results intrigued the case companies in the ICT field into investing their time in the research project. Future studies conducted by several researchers, in other areas of industry, in several geographical locations, or focusing entirely on, for instance, start-ups would broaden our understanding and fill in the knowledge gaps to create a theory about leadership toward creativity in virtual work.

Future studies could be executed on the network level to further cover customers' and other stakeholders' creativity. Both qualitative and quantitative research methods could be applied. Moreover, longitudinal studies are highly recommended to build an overall stronger evidence base. An additional direction for future research is to explore the role of materialities in leadership toward creativity in virtual work. A better understanding, for instance, of the role of social media in supporting creativity in virtual work would be useful for both academics and practitioners. For researchers interested in leadership development, one future research direction in virtual work could be to explore how a person's background, especially in team sports, music bands, or coaching, influences her success as a leader.

Concerning the role of learning and supporting knowledge utilization in virtual dispersed work toward creativity, it would be fruitful in the future to shift the focus from leaders to employees and study the role of staff members in supporting each other to foster creativity in virtual work. This knowledge could also help practitioners to tackle different organizational changes and emotional baggage from the previous organizations.

Finally, further research could aim to create a theory that also explains the outcomes of leadership towards creativity in the virtual world.

Although further work is required to gain a complete understanding of leadership toward creativity in virtual work, the findings of this study indicate that combining creativity-conducted leadership approaches and the heterarchy perspective in leadership would enable both people and businesses to flourish in the digital era.

\section{REFERENCES}


Typology on Leadership toward Creativity in Virtual Work

Aarnio, H., \& Enqvist, J. (2016). Uudistettu DIANA-malli kehykseksi digiajan oppimiselle. Journal of Professional and Vocational Education, 18(3), 39-48.

Adler, P. S. (2001). Market, hierarchy, and trust: The knowledge economy and the future of capitalism. Organization Science, 12(2), 215-234.

Agrifoglio, R., \& Metallo, C. (2011). Virtual environment and collaborative work: The role of relationship quality in facilitating individual creativity. In A. D'Atri, M. Ferrara, J. F. George, \& P. Spagnoletti (Eds.), Information technology and innovation trends in organizations (pp. 389-397). Berlin and Heidelberg: Springer-Verlag.

Aime, F., Humphrey, S., Scott, D. D., \& Paul, J. P. (2014). The riddle of heterarchy: Power transitions in crossfunctional teams. Academy of Management Journal, 57(2), 327-352.

Alexander, T. M. (1987). John Dewey's theory of art, experience, and nature: The horizons of feelings. Albany, NY: State University of New York Press.

Altschuller, S., \& Benbunan-Fich, R. (2010). Trust, performance, and the communication process in ad hoc decision-making virtual teams. Journal of Computed-Mediated Communication, 16(1), 27-47.

Alvesson, M., \& Karreman, D. (2011). Qualitative research and theory development: Mystery as method. London: Sage Publications Ltd.

Amabile, T. M. (1983). Social psychology of creativity: A componential conceptualization. Journal of Personality and Social Psychology, 45(2), 357-376.

Amabile, T. M. (1988). A model of creativity and innovation in organizations. Research in Organizational Behavior, 10, 123-167.

Amabile, T. M. (1998). How to kill creativity. Harvard Business Review, 76(5), 76-87.

Amabile, T. M., Barsade, S. G., Mueller, J. S., \& Staw, B. M. (2005). Affect and creativity at work. Administrative Science Quarterly, 50(3), 367-403.

Amabile, T. M., Conti, R., Coon, R., Lazenby, J., \& Herron, M. (1996). Assessing the work environment for creativity. Academy of Management Journal, 39(5), 1154-1184.

Amabile, T. M., \& Khaire, M. (2008). Creativity and the role of the leader. Harvard Business Review, 86(10), 100109.

Amabile, T. M., \& Kramer, S. J. (2010). What really motivates workers? Harvard Business Review, 88(1), 44-45.

Amabile, T., \& Kramer, S. (2011). The progress principle: Using small wins to ignite joy, engagement and creativity at work. Brighton, MA: Harvard Business Review Press.

Avolio, B. J., \& Bass, B. M. (1988). Transformational leadership, charisma and beyond. In Hunt, J. G., Baliga, B. R., Dachler, H. P., \& Schriesheim, C. A. (Eds.), Emerging leadership vistas (pp. 29-49). Boston, MA: Lexington.

Avolio, B. J., Waldman, D. A., \& Yammarino, F. J. (1991). The four I's of transformational leadership. Journal of European Industrial Training, 15(4), 9-16.

Bar-On, R. (2004). The Bar-On emotional quotient inventory (EQ-I): Rationale, description and summary of psychometric properties. In Geher, G. (Ed.), Measuring emotional intelligence: Common ground and controversy (pp. 115-145). New York: Nova Science Publishers, Inc.

Bass, B., \& Avolio, B. (1993). Transformational leadership and organizational culture. Public Administration Quarterly, 17(1), 112-121.

Bell, B. S., \& Kozlowski, S. W. J. (2002). A typology of virtual teams: Implications for effective leadership. Group \& Organization Management, 27(1), 14-49.

Bissola, R., \& Imperatori, B. (2011). Organizing individual and collective creativity: Flying in the face of creativity clichés. Creativity and Innovation Management, 20(2), 77-89.

Borgmann, L., Rowold, J., \& Bormann, K.-C. (2016). Integrating leadership research: A meta-analytical test of Yukl's meta-categories of leadership. Personnel Review, 45(6), 1340-1366. 
Boyatzis, R. E., \& Sala, F. (2004). The emotional competence inventory (ECI). In Geher, G. (Ed.), The measurement of emotional intelligence (pp. 147-180). Hauppauge, NY: Nova Science Publishers.

Brinkmann, S. (2012). Qualitative inquiry in everyday life: Working with everyday life materials. Thousand Oaks, CA: SAGE Publications Ltd.

Brinkmann, S. (2014). Doing without data. Qualitative Inquiry, 20(6), 720-725.

Brynjolfsson, E., \& McAfee, A. (2014). The second machine age: Work, progress, and prosperity in a time of brilliant technologies. New York and London: W.W. Norton \& Company.

Burns, J. M. (1978). Leadership. New York: Harper \& Row.

Castro, F., Gomes, J., \& de Sousa, F. C. (2012). Do intelligent leaders make a difference? The effect of a leader's emotional intelligence on followers' creativity. Creativity and Innovation Management, 21(2), 171-181.

Catmull, E., \& Wallace, A. (2014). Creativity, Inc.: Overcoming the unseen forces that stand in the way of true inspiration. London: Bantam Press.

Chamakiotis, P. (2014). Exploring creativity in temporary virtual teams: The case of engineering design (Doctoral dissertation, University of Bath). Retrieved from http://opus.bath.ac.uk/40989/

Chumg, H.-F., Cooke, L., Fry, J., \& Hung, I.-H. (2015). Factors affecting knowledge sharing in the virtual organization: Employees' sense of well-being as a mediating effect. Computers in Human Behavior, 44, 70-80.

Clemen, R.T., \& Reilly, T. (2014). Making hard decisions with decision tools ${ }^{\circledR} 3^{\text {rd }}$ ed.). Mason, OH: South-Western Cengage Learning.

Clippinger, J. H. III (1999). Order from the bottom up: Complex adaptive systems and their management. In J. H. Clippinger III (Ed.), The biology of business: Decoding the natural laws of enterprise (pp. 1-30). San Francisco: Jossey-Bass Publishers.

Coleman, D. (1998). What makes a leader? Harvard Business Review, 76(6), 93-102.

Coleman, D. (2001). Emotional intelligence: Issues in paradigm building. In C. Cherniss, \& D. Coleman (Eds.), The emotionally intelligent workplace (pp. 13-26). San Francisco: Jossey-Bass.

Coleman, D. (2006). Social intelligence: The new science of human relationships. New York: Bantam Dell.

Coleman, D., Boyatzis, R., \& McKee, A. (2004). Primal leadership: Learning to lead with emotional intelligence. Boston: Harvard Business Review Press.

Collier, D., LaPorte, J., \& Seawright, J. (2012). Putting typologies to work: Concept formation, measurement, and analytic rigor. Political Research Quarterly, 65(1), 217-232.

Cortini, M., \& Scaratti, G. (2011). Creativity at work and weblogs: Opportunities and obstacles. In A. D'Atri, M. Ferrara, J. F. George, \& P. Spagnoletti (Eds.), Information technology and innovation trends in organizations (pp. 443-450). Berlin and Heidelberg: Springer-Verlag.

Countlett, D. (2011). Making is connecting: The social meaning of creativity, from DIY and knitting in YouTube and Web 2.0. Cambridge, UK: Polity Press.

Crevani, L., Lindgren, M., \& Packendorff, J. (2010). Leadership, not leaders: On the study of leadership as practices and interactions. Scandinavian Journal of Management, 26(1), 77-86.

Crumley, C. L. (1995). Heterarchy and the analysis of complex societies. Archaeological Papers of the American Anthropological Association, 6(1), 1-5.

Crumley, C. L. (2001). Communication, holism, and the evolution of sociopolitical complexity. In J. Haas (Ed.), From leaders to rulers (pp. 19-33). New York: Kluwer Academic/Plenum Publishers.

Crumley, C. L. (2005). Remember how to organize: Heterarchy across disciplines. In C. S. Beekman, \& W. S. Baden (Eds.), Nonlinear models for archaeology and anthropology (pp. 35-50). Adlershot, UK: Ashgate Press.

Csikszentmihalyi, M. (1999). A Systems perspective on creativity. Edited extract from Sternberg, R. (Ed.), Handbook of creativity (pp. 313-335). Cambridge: Cambridge University Press. Retrieved from https://www.sagepub.com/sites/default/files/upm-binaries/1144301 Henry Ch01.pdf 
Typology on Leadership toward Creativity in Virtual Work

Dawson, S., \& Siemens, G. (2014). Analytics to literacies: The development of a learning analytics framework for multiliteracies assessment. The International Review of Research in Open and Distributed Learning, 15(4), 284305.

Dekkers, R. (2009). Epilogue. In R. Dekkers (Ed.), Dispersed manufacturing networks: Challenges for research and practice (pp. 241-250). London: Springer.

Derecskei, A. (2016). How do leadership styles influence the creativity of employees? Society and Economy, 38(1), 103-118.

Derue, D. S., Nahrgang, J. D., Wellman, N., \& Humphrey, S. E. (2011). Trait and behavioral theories of leadership: An integration and meta-analytic test of their relative validity. Personnel Psychology, 64(1), 7-52.

Dewey, J. (1938). Logic: The theory of inquiry. New York: Henry Holt \& Company.

Dinh, J. E., Lord, R. G., Gardner, W. L., Meuser, J. D., Liden, R. C., \& Hu, J. (2014). Leadership theory and research in the new millennium: Current theoretical trends and changing perspectives. The Leadership Quarterly, 25(1), 36-62.

Dixon, K. R. \& Panteli, N. (2010). From virtual teams to virtuality in teams. Human Relations, 63(8), 1177-1197.

Dotlich, D., Cairo, P. \& Rhinesmith, S. (2008). Complexity, diversity, and uncertainty: The shaky new ground for CEOs. People and Strategy, 31(2), 44-51.

Drazin, R., Kazanjian, R. J., \& Glynn, M. (2008). Creativity and sensemaking among professionals. In J. Zhou \& C. E. Shalley (Eds.), Handbook of organizational creativity (pp. 263-281). New York and London: Lawrence Erlbaum Associates.

Dubé, L., Bourhis, A., \& Jacob, R. (2006). Towards a typology of virtual communities in practice. Interdisciplinary Journal of Information, Knowledge, and Management, 1(1), 63-93. Retrieved from http://www.ijikm.org/Volume1/IJIKMv1p069-093Dube.pdf

Eisenbeiß, S. A, \& Boerner, S. (2013). A double-edged sword: Transformational leadership and individual creativity. British Journal of Management, 24(1), 54-68.

Frye, C. M., Bennett, R., \& Caldwell, S. (2006). Team emotional intelligence and team interpersonal process effectiveness. Mid-American Journal of Business, 21(1), 49-56.

Gartner, H. (1983). Frames of mind: The theory of multiple intelligences. New York: Basic Books.

Geerlof, J., \& van Beckhoven, A. (2016). Complexity, self-organization and leadership: Enlivened experiences from The Netherlands. Integral Leadership Review, 16(2). Retrieved from http://integralleadershipreview.com/14633-complexity-self-organization-and-leadership-enlivened-experiences-from-the-netherla/

Gibson, C. B., \& Gibbs, J. L. (2006). Unpacking the concept of virtuality: The effects of geographic dispersion, electronic dependence, dynamic structure, and national diversity on team innovation. Administrative Science Quarterly, 51(3), 451-495.

Gilson, L. L., Maynard, M. T., Jones Young, N. C., Vartiainen, M., \& Hakonen, M. (2015). Virtual teams research: 10 years, 10 themes and 10 opportunities. Journal of Management, 41(5), 1313-1337.

Girard, M., \& Stark, D. (2002). Distributing intelligence and organizing diversity in new-media projects. Environment and Planning A, 34(9), 1927-1949.

Goldstein, J., Hazy, J. K., \& Lichtenstein, B. B. (2010). Complexity and the nexus of leadership: Leveraging nonlinear science to create ecologies of innovation. New York: Palgrave Macmillan.

Grant, A. M. (2012). Leading with meaning: Beneficiary contact, prosocial impact, and the performance effects of transformational leadership. Academy of Management Journal, 55(2), 458-476.

Griffith, T. L., Sawyer, J. E., \& Neale, M. A. (2003). Virtualness and knowledge in teams: Managing the love triangle of organizations, individuals, and information technology. MIS Quarterly, 27(2), 265-287.

Gros, B. (2016). The dialogue between emergent pedagogies and emergent technologies. In B. Gros, Kinshuk, \& M. Maina (Eds.), The future of ubiquitous learning: Learning designs for emerging pedagogies (pp. 3-23). Berlin and Heidelberg: Springer-Verlag. 
Gruber, T. R. (1995). Toward principles for the design of ontologies used for knowledge sharing. International Journal of Human-Computer Studies, 43(5-6), 623-965.

Guo, J., Dilley, A. E., \& Gonzales, R. (2016). Creativity and leadership in organizations: A literature review. Creativity: Theories - Research - Applications, 3(1), 127-151.

Handy, C. (1995). Trust and the virtual organization. Harvard Business Review, 73(3), 40-50.

Hara, N., Shachaf, P., \& Stoerger, S. (2009). Online communities of practice typology revisited. Journal of Information Science, 35(6), 740-757.

Hardagon, A. B., \& Bechky, B. A. (2006). When collections of creatives become creative collectives: A field study of problem solving at work. Organization Science, 17(4), 484-500.

Hatch, M. J., \& Cunliffe, A. L. (2006). Organization theory: Modern, symbolic, and post-modern perspectives. Oxford, UK: Oxford University Press.

Hazy, J. K. (2009). Innovation reordering: five principles for leading continuous renewal. In S. Schlomer \& N. Tomaschek (Eds.), Leading in complexity: New ways of management (pp. 40-56). Heidelberg: Systemische Forschung im Car-Auer Verlag.

Hoch, J. E., \& Kozlowski, W. J. (2014). Leading virtual teams: Hierarchical leadership, structural supports, and shared team leadership. Journal of Applied Psychology, 99(3), 390-403.

Holland, J. H. (2006). Studying complex adaptive systems. Journal of Systems Science and Complexity, 19(1), 1-8.

Houglum, D. T. (2012). Myth-busters: Traditional and emergent leadership. Emergence: Complexity \& Organization (E:CO), 14(2), 25-39.

Hu, H., Gu, Q., \& Chen, J. (2013). How and when does transformational leadership affect organizational creativity and innovation? Critical review and future directions. Nankai Business Review International, 4(2), $147-$ 166.

Humala, I. (2014). Defining leadership that fosters creativity in virtual work: Descriptive interpretative concept analysis. Journal of Professional and Vocational Education, 16(3), 22-43.

Humala, I. (2015). Leadership toward creativity in virtual work in a start-up context. Journal of Workplace Learning, 27(6), 426-441.

Humala, I. (2016). Heterarchial ontological commitment for leaders to stimulate creativity among virtual workforce. Nordic Journal of Business, 65(2), 45-65.

Hyypiä, M. \& Parjanen, S. (2013). Boosting creativity with transformational leadership in fuzzy front-end innovation leadership processes. Interdisciplinary Journal of Information, Knowledge, and Management, 8, 21-40. Retrieved from http://www.ijikm.org/Volume8/IJIKMv8p021-041Hyypia0678.pdf

Hämäläinen, R., \& Vähäsantanen, K. (2011). Theoretical and pedagogical perspectives on orchestrating creativity and collaborative learning. Educational Research Review, 6(3), 169-184.

Jago, A. G., \& Vroom, V. H. (1977). Hierarchical level and leadership style. Organizational Behavior and Human Performance, 18, 131-145.

Jakonen, J. P., \& Kamppinen, M. (2015). Creating wisdom cultures: Integral coaching as applied foresight in leadership development. Approaching Religion, 5(2), 15-26.

Jakonen, J. P. \& Kamppinen, M. (2016). Kohti kokonaisuksien hahmottamista - Ken Wilbergin integraaliteoria. In E. Kallio (Ed.), Ajattelun kehitys aikuisundessa - kobti moninäkökulmaisuutta (pp. 321-353). Jyväskylä: FERA, Suomen kasvatustieteellinen seura ry.

Jarvenpaa, S. L., \& Leidner, D.E. (1999). Communication and trust in global virtual teams. Organization Science, 10(6), 791-815.

Jenster, N. P., \& Steiler, D. (2011). 'Turning up the volume' in inter-personal leadership: Motivating and building cohesive global virtual teams during times of economic crisis. In W. H. Obley, M. Li, \& Y. Wang (Eds.), Advances in global leadership (Volume 6) (pp. 267-297). London: Emerald Group Publishing Limited. 
Typology on Leadership toward Creativity in Virtual Work

Johnson, P. (2015). Creativity in a real-time world: Improvisation and the culture of creativity. Journal of Business Anthropology, 4(2), 265-273.

Kahai, S. S., Huang, R, \& Jestice, R. J. (2012). Interaction effect of leadership and communication media on feedback positivity in virtual teams. Group \& Organization Management, 37(6), 716-751.

Kallio, T. J., \& Kallio, K.-M. (2011). Organisatorinen luovuus - hypestä kohti luovuuden mahdollistavia organisaatiorakenteita. Liiketaloudellinen Aikakauskirja, 1(2011), 33-64.

Karwowski, M. (2014). Creative mindsets: Measurement, correlates, consequences. Psychology of Aesthetics, Creativity, and the Arts, 8(1), 62-70.

Kupiainen, R., \& Sintonen, S. (2010). Media literacy as a focal practice. In S. Kotilainen \& S.-B. ArnoldsGranlund, (Eds.), Media literacy education: Nordic perspectives (pp. 57-68), Göteborg: Nordicom.

Langley, A., \& Tsoukas, H. (2010). Introducing “perspectives on process organization studies". In T. Hernes \& S. Maitlis (Eds.), Process, sensemaking, and organizing (pp. 1-26). Oxford, UK: Oxford University Press.

Lewis, M. (2010). Virtual project teams: The role of empathy and social intelligence in the development of trust. Unpublished doctoral dissertation, University of Phoenix, AZ.

Lichtenstein, B. B., Uhl-Bin, M., Marion, R., Seers, A., \& Orton, J. D. (2006). Complexity leadership theory: An interactive perspective on leading complex adaptive systems. Emergence: Complexity and Organization, 8(4), 212.

Lipnack, J., \& Stamps, J. (1999). Virtual teams: The new way to work. Strategy \& Leadership, 27(1), 14-19.

Lips-Wiersma, M., \& Wright, S. (2012). Measuring the meaning of meaningful work: Development and validation of the comprehensive meaningful work scale (CMWS). Group \& Organization Management, 37(5), 655685.

Martens, Y. (2011). Creative workplace: Instrumental and symbolic support for creativity. Facilities, 29(1), 63-79.

Mayer, J. D., \& Salovey, P. (1997). What is emotional intelligence? In P. Salovey \& D. J. Sluyter (Eds.), Emotional development and emotional intelligence: Implications for educators (pp. 3-31). New York: Basic Books.

McCulloch, W. S. (1945). A heterarchy of values determined by the topology of neural nets. Bulletin of Mathematical Biophysics, 7, 89-93.

McGuire, J. B., Palus, C. J., Pasmore, W., \& Rhodes, G. B. (2015). Transforming your organization. Greensboro, NC: Center for Creative Leadership. Retrieved from https://www.ccl.org/wp-content/uploads/2015/04/TYO.pdf

Mittal, S., \& Dhar, R. L. (2015). Transformational leadership and employee creativity: Mediating role of creative self-efficacy and moderating role of knowledge sharing. Management Decision, 53(5), 894-910.

Moeran, B. (2015). A Prolegomenon: All about creativity and innovation. Journal of Business Anthropology, 4(2), $228-235$.

Mononen, L., Tynjälä, P., \& Kallio, E. (2016). Systeemiajattelu - monitieteinen näkökulma kokonaisvaltaiseen ajatteluun. In E. Kallio (Ed.) Ajattelun kehitys aiknisundessa - kobti moninäkökulmaisuntta (pp. 297-319). Jyväskylä: FERA, Suomen kasvatustieteellinen seura ry.

Nie, Y., \& Kosaka, M. (2014). A new perspective on leadership for achieving servitization of business. Journal of Management Research, 6(4), 50-62.

Nokelainen, P., \& Ruohotie, P. (2006). Johtamisen tunneäly työntekijöiden kokemana. Journal of Professional and Vocational Education, 8(1), 62-72.

Ocker, R. J. (2005). Influences on creativity in asynchronous virtual teams: A qualitative analysis of experimental teams. IEEE Transactions on Professional Communication, 48(1), 22-39.

O'Connor, R. V. (2016). Toward an understanding of team dynamics in very small enterprises: An explorative study in software development firms. In M. Russ (Ed.), Quantitative multidisciplinary approaches in buman capital and asset management (pp. 42-64). Hershey, PA: Business Science Reference. 
O’Leary, M. B., Wilson, J. M., \& Metiu, A. (2014). Beyond being there: The symbolic role of communication and identification in perceptions of proximity to geographically dispersed colleagues. MIS Quarterly, 38(4), 1219-1243.

Osborn, R., Uhl-Bien, M., \& Milosevic, I. (2014). The context and leadership. In D. Day (Ed.), The Oxford handbook of leadership and organizations (pp. 589-612). Oxford, UK: Oxford University Press.

Panteli, N. (2004). Situating trust within virtual teams. In S. Reddy (Ed.), Virtual teams: Contemporary insights. Hyderabad, India: ICFAI University Press.

Panteli, N. (2009). Virtual social networks: A new dimension for virtuality research. In N. Panteli (Ed.), Virtual social networks: Mediated, massive and multiplayer sites. Hampshire, UK: Palgrave-Macmillan.

Panteli, N., \& Chiasson, M. (2008). Exploring virtuality within and beyond organizations: Social, global and local dimensions. Hampshire and New York: Palgrave Macmillan.

Parjanen, S. (2012). Creating possibilities for collective creativity: Brokerage functions in practice-based innovation. (Doctoral dissertation, Lappeenranta University of Technology, Finland). Retrieved from https://www.doria.fi/bitstream/handle $/ 10024 / 76983 /$ isbn $\% 209789522652348$.pdf? sequence $=1$

Penttilä, T., \& Hakala, J. T. (2016). Innovation competence as part of the new hybrid professions. Journal of Professional and Vocational Education, 18(2), 46-53.

Pinar, T., Zehir, C., Kitapçı, H., \& Tanrıverdı, H. (2014). The relationships between leadership behaviors: Team learning and performance among the virtual teams. International Business Research, 7(5), 68-79.

Plowman, D. A., Solansky, S., Beck, T. E., Baker, L., Kulkarni, M., \& Villareal Travis, D. (2007). The role of leadership in emergent, self-organization. The Leadership Quarterly, 18(4), 341-356.

Post, D. G. (2001). Anarchy, state and the internet: An essay on lawmaking in cyberspace. In P. Ludlow (Ed.), Crypto anarchy, cyberstates, and pirate utopias (pp. 197-212). Cambridge and London: The MIT Press.

Prasad, B. (2014). The emergence of a collective mind: Knowledge management in a $21^{\text {st }}$ century enterprise. Mooresville, NC: Eminnode LLC.

Porges, S. W. (2011). The polyvagal theory: Neurophysiological foundations of emotions, attachment, communication, and selfregulation. New York \& London: W.W. Norton \& Company.

Poutanen, P. (2016). Complexity and collaboration in creative group work (Doctoral dissertation, University of Helsinki). Retrieved from https://helda.helsinki.fi/bitstream/handle/10138/162813/COMPLEXI.pdf?sequence $=1$

Purvanova, R. K., \& Bono, J. E. (2009). Transformational leadership in context: Face-to-face and virtual teams. The Leadership Quarterly, 20(3), 343-357.

Quisenberry, W. L. (2011). Common characteristics and attributes of self-managed virtual teams. (Unpublished doctoral dissertation). Walden University, Minneapolis, MN.

Reeves, T. C., Herrington, J., \& Oliver, R. (2002, July). Authentic activities and online learning. In J. Herrington (Ed.), Proceedings of the 25th HERDS A Annual Conference (pp. 562-567). Perth: Edith Cowan University. Retrieved from http://ro.ecu.edu.au/cgi/viewcontent.cgi?article=4899\&context=ecuworks

Ruggieri, S. (2009). Leadership in virtual teams: A comparison of transformational and transactional leaders. Social Behavior and Personality, 37(8), 1017-1022.

Ruggieri, S., Boca, S., \& Garro, M. (2013). Leadership styles in synchronous and asynchronous virtual learning environments. The Turkish Online Journal of Educational Technology, 12(4), 96-101.

Sawyer, R. K., \& DeZutter, S. (2009). Distributed creativity: How collective creations emerge from collaboration. Psychology of Aesthetics, Creativity, and the Arts, 3(2), 81-92.

Schepers, P., \& van den Berg, P. T. (2007). Social factors of work-environment creativity. Journal of Business and Psychology, 21(3), 407-428.

Searle, G. D., \& Hanrahan, S. J. (2011). Leading to inspire others: charismatic influence or hard work? Leadership \& Organization Development Journal, 32(7), 736-754. 
Typology on Leadership toward Creativity in Virtual Work

Seeck, H., \& Kantola, A. (2009) Organizational control: Restrictive or productive? Journal of Management and Organization, 15(2), 241-257.

Schultz, R. W. (2010). Exploring leadership within the modern organization: Understanding the dynamics of effective leadership of a virtual, multigenerational workforce. (Unpublished doctoral dissertation). Capella University, Minneapolis, MN.

Spelthann, V., \& Haunschild, A. (2011). Organizational creativity in heterarchies: The case of VFX production. Creativity and Innovation Management, 20(2), 100-107.

Stark, D. (2009). The sense of dissonance: Accounts of worth in economic life. Princeton and Oxford: Princeton University Press.

Staw, B. M. (2016). Stumbling toward a social psychology of organizations: An autobiographical look at the direction of organizational research. Annual Review of Organizational Psychology and Organizational Behavior, 3, 1 19.

Stephenson, K. (2009). Neither hierarchy nor network: An argument for heterarchy. People \& Strategy, 32(1), 47.

Tierney, P., \& Farmer, S. M. (2002). Creative self-efficacy: its potential antecedents and relationship to creative performance. Academy of Management Journal, 45(6), 1137-1148.

Thow, Y. L. (2007). The new intelligence leadership strategy for iCAS. Human Systems Management, 26(2), 111 122.

Toom, A. (2016). Hiljainen tieto ja asiantuntijuus. In E. Kallio (Ed.), Ajattelun kehitys aikuisuudessa - kobti moninäkökulmaisuutta (pp. 245-268). Jyväskylä: FERA, Suomen kasvatustieteellinen seura ry.

Tost, L. P., Gino. F., \& Larrick, R. P. (2013). When power makes others speechless: The negative impact of leader power on team performance. Academy of Management Journal, 56(5), 1465-1586.

Uhl-Bien, M., Marion, R., \& McKelvey, B. (2007). Complexity leadership theory: Shifting leadership from the industrial age to the knowledge era. The Leadership Quarterly, 18(4), 298-318.

Uusikylä, K. (2012). Luovuus kuuluu kaikille. Jyväskylä: PS-kustannus.

Virtanen, M. (2013). Opettajan emotionaalinen kompetenssi: Tutkimus luokanopettajien ja luokanopettajiksi opiskelevien tunneälytaidoista ja niiden tärkeydestä. (Unpublished doctoral dissertation). Acta Electronica Universitatis Tamperensis 1301. Tampere: University of Tampere.

Vygotsky, L. (1978). Mind and society. Cambridge, MA: Harvard University Press.

Wang, P., \& Rode, J.C. (2010). Transformational leadership and follower creativity: The moderating effects of identification of leaders and organizational climate. Human Relations, 63(8), 1105-1128.

Wang, P., \& Zhu, W. (2011). Mediating role of creative identity in the influence of transformational leadership on creativity: Is there a multilevel effect? Journal of Leadership \& Organizational Studies, 18(1), 25-39.

Warrick, D. D. (2011). The urgent need for skilled transformational leaders: Integrating transformational leadership and organization development. Journal of Leadership, Accountability and Ethics, 8(5), 11-26.

Weil, M. (2009). Rethinking a network approach in vocational education research. In M. Weil, L. Koski, \& L. Mjelde (Eds.), Knowing work: The social relations of working and knowing (pp. 209-229). Bern: Peter Lang AG.

Wheeler, S., Waite, S. J., \& Bromfield, C. (2002). Promoting creative thinking through the use of ICT. Journal of Computer Assisted Learning, 18(3), 367-378.

Whitford, T., \& Moss, S. A. (2009). Transformational leadership in distributed work groups: The moderating role of follower regulatory focus and goal orientation. Communication Research, 36(6), 810-837.

Wilson, J. M., O’Leary, M. B., Metiu, A., \& Jett, Q. R. (2008). Perceived proximity in virtual work: Explaining the paradox of far-but-close. Organization Studies, 29(7), 979-1002.

Woodman, R. W., Sawyer, J. E., \& Griffin, R. W. (1993). Toward a theory of organizational creativity. Academy of Management Review, 18(2), 293-321. 
Yukl, G., Gordon, A., \& Taber, T. (2002). A hierarchical taxonomy of leadership behavior: Integrating a half century of behavior research. Journal of Leadership \& Organizational Studies, 9(1), 15-32.

Zayani, F. A. (2008). The impact of transformational leadership on the success of global virtual teams: An investigation based on the multifactor leadership questionnaire. (Unpublished doctoral dissertation). Minneapolis, MN: Capella University.

Zhou, J., \& Shalley, C. E. (2008). Expanding the scope and impact of organizational creativity research. In J. Zhou \& C. E. Shalley (Eds.), Handbook of organizational creativity (pp. 347-368). New York and London: Lawrence Erlbaum Associates.

Zimmermann, P., Wit, A., \& Gill, R. (2008). The relative importance of leadership behaviours in virtual and face-to-face communication settings. Leadership, 4(3), 321-337.

Zohar, D. (1997). Rewiring the corporate brain: Using the new science to retbink, how we structure and lead organizations. San Francisco: Berrett-Koehler Publishers.

\section{BIOGRAPHY}

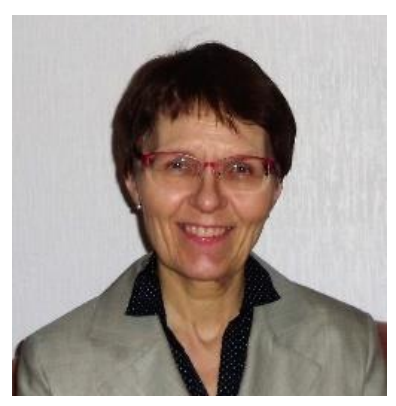

Iris Humala is a Doctoral candidate in the Faculty of Education, University of Tampere, Finland. She has a PhD degree in Economics and Business Administration from University of Vaasa, Finland. She has a broad experience in program and project management, research management and consulting. Her current research interests are in the areas of leadership in virtual work and business networks. Now she is working in Iris Consulting ky as entrepreneur and coach. 